University of Redlands

\title{
Identifying Target Market Areas for Major League Soccer Using GIS
}

\author{
A Major Individual Project submitted in partial satisfaction of the requirements \\ for the degree of Master of Science in Geographic Information Systems \\ by \\ Gregory James Packer \\ Fang Ren, Ph.D., Committee Chair \\ Mark Kumler, Ph.D.
}

February 2012 


\section{Identifying Target Market Areas for Major League Soccer Using GIS}

Copyright $\odot 2012$

by

Gregory James Packer 
The report of Gregory James Packer is approved.

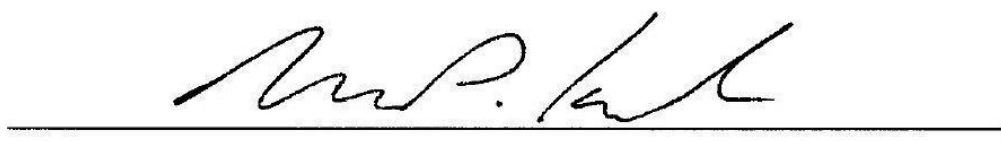

Mark Kumler, Ph.D.

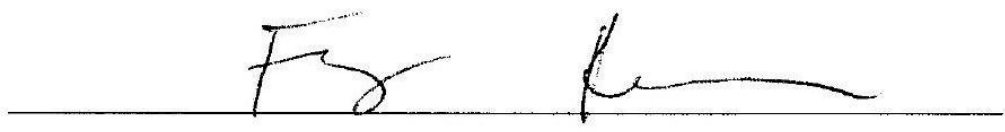

Fang Ren, Ph.D., Committee Chair

February 2012 



\section{Acknowledgements}

I express appreciation to Brett Lashbrook, Legal Counsel and Special Assistant to Major League Soccer's Commissioner's Office, for accepting my research proposal and for his indispensible assistance in facilitating this process through connecting me with the appropriate persons and ensuring raw data was provided me for the analysis. I am likewise indebted to Russ Findlay, Chief Marketing Officer for Major League Soccer, Stuart Crystal, Handler of MLS Licensing, and Rodrigo Morales Abiega, Vice President of Marketing and Sponsorship for Club Deportivo Chivas USA. I appreciate greatly the help I have received from Esri instructor Colin Childs, especially for his introducing me to Esri's Business Analyst. I also owe much to my thesis advisor, Fang Ren, as well as the entire faculty at the University of Redlands' Master of Science in Geographic Information Systems program for their enthusiasm for and guidance in this project. 



\begin{abstract}
Identifying Target Market Areas for Major League Soccer Using GIS

by

Gregory James Packer
\end{abstract}

Since its inaugural season in 1996, Major League Soccer (MLS) has developed steadily, growing from ten franchises at its inception to eighteen today, with plans to expand to twenty over the next two years. MLS was faced with some critical marketing questions to ensure that growth was coupled with stability. The League desired to know what types of neighborhoods their fans lived in and how far the fans were willing to travel to matches. They also wished to know where they might find similar neighborhoods to these, where they could market more effectively. Geographic information systems (GIS) were utilized with a year's season ticket sales for a single MLS club, Chivas USA, to conduct analysis. Demographic and socioeconomic information from Esri's Business Analyst was used, and research yielded several conclusions. These included a profile of the season-ticket holding neighborhoods, as well as suitable areas for marketing based on this profile. Further analysis of total MLS customers sales in southern California covering a four year period, as well as the general population in the same region, substantiated these conclusions. The methodology used for this project can be used for further MLS (or other sports) teams' marketing strategies. 



\section{Table of Contents}

Chapter 1 - Introduction ......................................................................................... 1

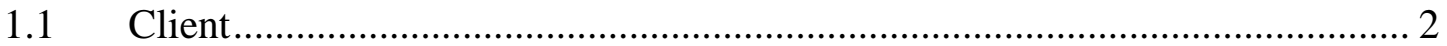

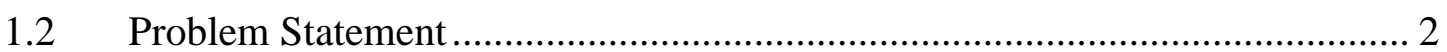

1.3 Proposed Solution ................................................................................... 2

1.3.1 Goals and Objectives ......................................................................... 3

1.3.2 Scope

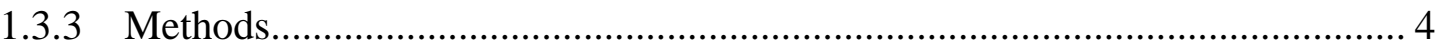

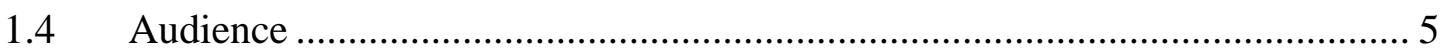

1.5 Overview of the Rest of this Report …………............................................. 5

Chapter 2 - Background and Literature Review ................................................................ 7

2.1 American Soccer and Marketability Factors................................................. 7

2.1.1 Relevant Determinants of Sport Attendance................................................ 9

2.1.2 Income

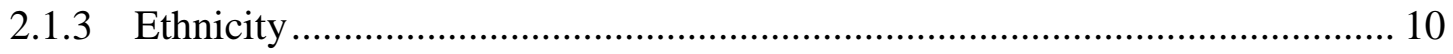

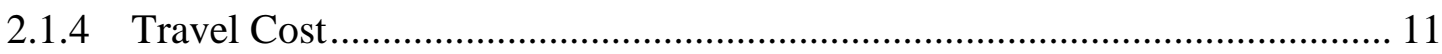

2.2 Sports Marketing and GIS ……………………...................................... 12

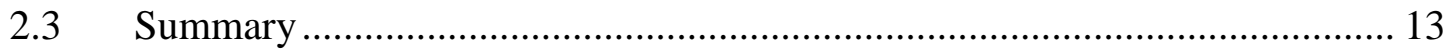

Chapter 3 - Project Plan................................................................................................................ 15

3.1 Problem Statement .................................................................................. 15

$3.2 \quad$ Requirements Analysis ........................................................................ 15

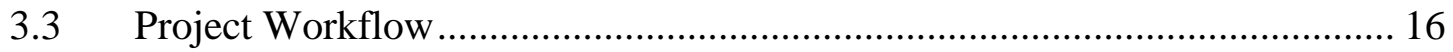

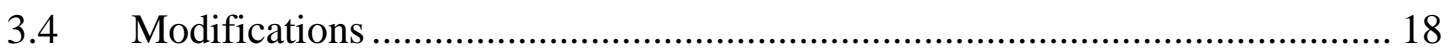


3.5 Summary

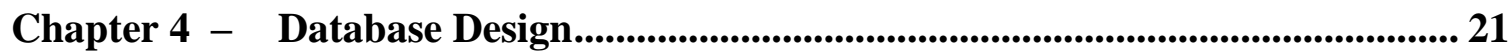

4.1 Conceptual Data Model ...................................................................... 21

4.2 Logical Data Model ................................................................................ 22

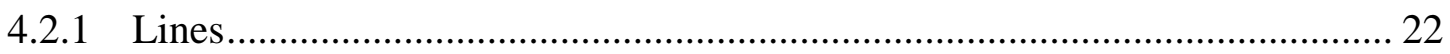

4.2.2 Points................................................................................................. 23

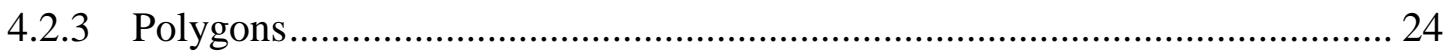

4.2.4 Raster Datasets, Toolbox, and Marketability Feature Dataset........................ 25

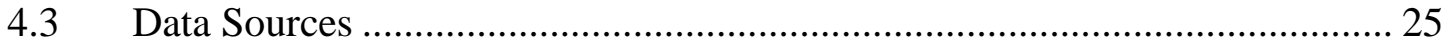

4.4 Data Scrubbing and Loading ……………………….............................. 26

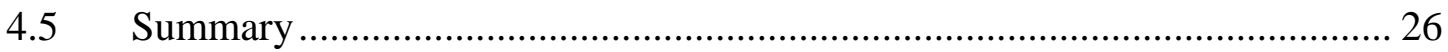

Chapter 5 - Results and Analysis........................................................................................ 27

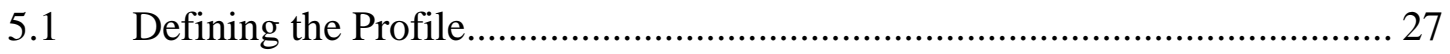

5.1.1 Spatial Patterns of Ticket Holders and Associated Neighborhoods ............... 28

5.1.2 Neighborhood Profiles Obtained from Community Tapestry ……………..... 33

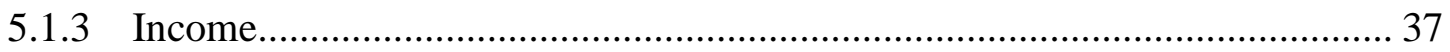

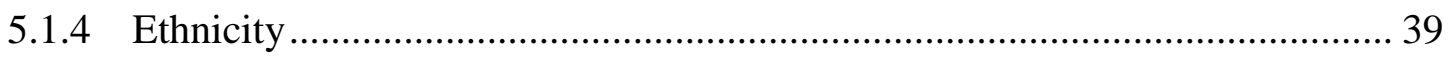

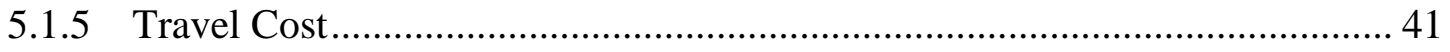

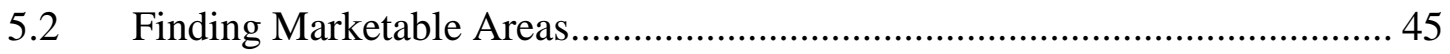

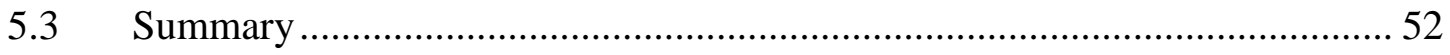

Chapter 6 - Conclusions and Future Work ....................................................................... 55

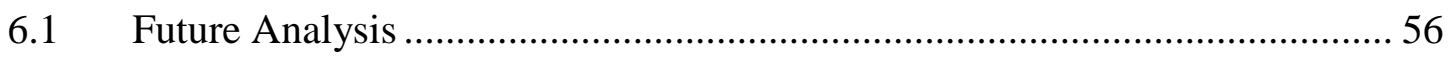

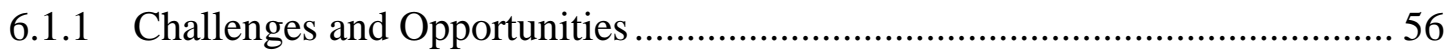


6.2 Final Conclusion.

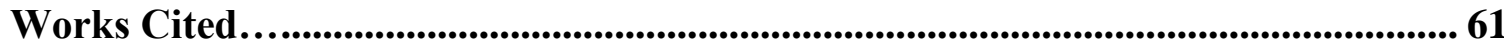

Appendix A. Esri Community Tapestry Descriptions................................................ 65 



\section{Table of Figures}

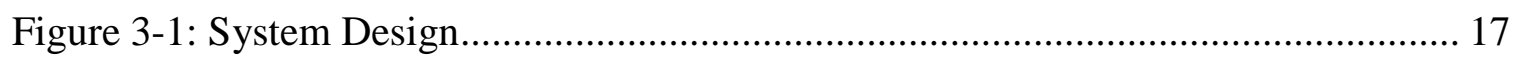

Figure 4-1: Conceptual Data Model ………………………………………………... 22

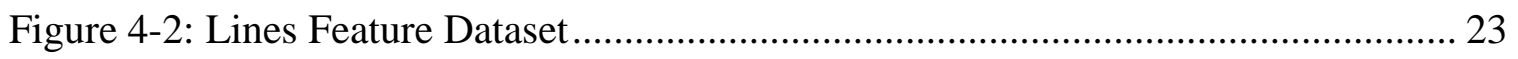

Figure 4-3: Points Feature Dataset............................................................................. 24

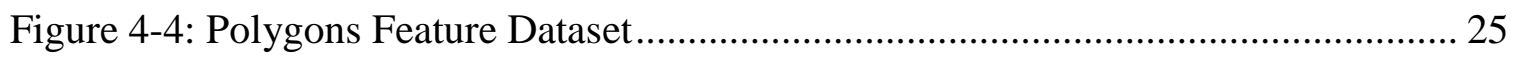

Figure 5-1: Addresses of Chivas Season Ticket Holders................................................ 29

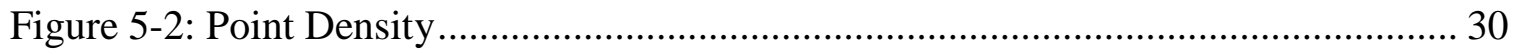

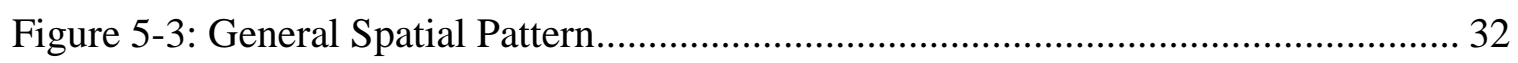

Figure 5-4: Chivas Community Tapestries Map............................................................. 35

Figure 5-5: Chivas Neighborhoods Income Map........................................................... 37

Figure 5-6: MLS and General Population Income Map................................................... 39

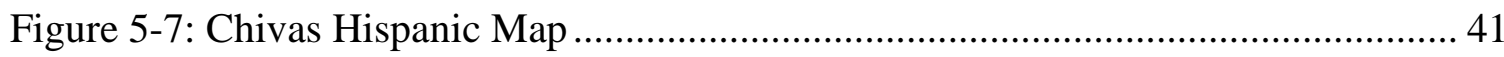

Figure 5-8: Chivas Drive Times to Matches Map............................................................ 43

Figure 5-9: Drive Times from all Southern California Neighborhoods Map ................... 44

Figure 5-10: Most Used Driving Routes to Matches Map ……………............................. 45

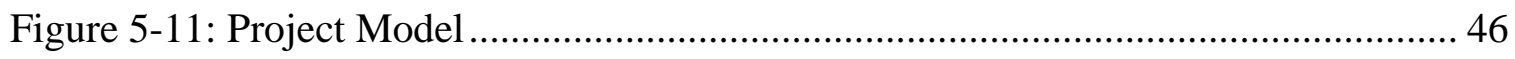

Figure 5-12: Individual Neighborhood Marketability Profiles Map.................................. 47

Figure 5-13: Final Marketability Map .................................................................... 48

Figure 5-14: Final Marketability Map Extended …………………………………..... 50

Figure 5-15: Chivas Neighborhoods \& Marketable Neighborhoods Map.......................... 52 


\section{List of Tables}

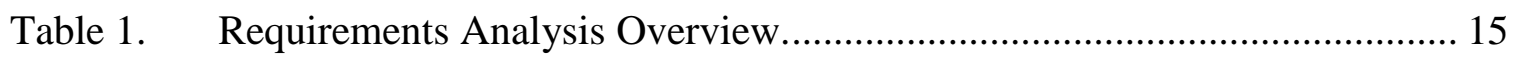

Table 2. Neighborhoods Represented in Chivas USA Data ................................... 34

Table 3. Community Tapestry Location Quotients.............................................. 36

Table 4. Location Quotients of Ethnicity ........................................................ 40 


\section{List of Acronyms}

BA

C.D. Chivas USA

Business Analyst. A software tool and dataset provided by Esri, containing substantial demographic and socioeconomic data for the United States and Canada.

Club Deportivo Chivas USA (English translation from Spanish: Sports Club Goats USA). A Major League Soccer club (team) based in the Los Angeles area, partially owned by and modeled after C.D. Guadalajara, an eminent soccer club in Mexico's top tier league, the Mexican Primera División. Referred to in this study by its commonly-shortened name of "Chivas USA" or simply "Chivas".

GIS Geographic Information Systems- "the software, hardware, procedures, data, personnel, and interconnecting network that facilitate the input, storage, processing, analysis, and presentation of spatial data" (Verjee, 2011).

HDC Home Depot Center, current home stadium of Chivas USA, located in Carson, California. Also the home stadium of fellow Major League Soccer club, Los Angeles Galaxy.

MLS

Major League Soccer. The top-tier professional soccer (or, association football) league in the United States.

SPSS

Statistical Package for the Social Sciences. A computer program developed by IBM specializing in statistical analysis.

UML Unified Modeling Language — a visualized model of objects and data displaying relationships and connections.

VGI Volunteered Geographic Information: "the harnessing of tools to create, assemble, and disseminate geographic data provided voluntarily by individuals" (Goodchild, 2007). 



\section{Chapter 1 - Introduction}

In 1975, international soccer superstar Pelé came to the United States to play for the struggling North American Soccer League's (NASL) New York Cosmos. His arrival initiated a soccer craze in America, where the sport was previously near-nonexistent, leading to rapid expansion for the league. But the growth was sporadic and teams were set up in cities that could not sustain them (Newsham, 2006). The league collapsed in 1984, but left a soccer legacy in the United States, leading to its World Cup hosting in 1994. Critics claimed the Cup would only be successful if soccer lived on in the U.S. after the tournament (Hellerman, \& Markovits, 2001). It did and Major League Soccer (MLS) opened with its inaugural season in 1996. Major League Soccer is determined not to repeat NASL's mistakes, by expanding only after careful analysis of current and potential markets.

Major League Soccer is a relatively new top-tier sports league in the United States and Canada. Comparatively, the National Basketball Association was founded in 1946, the National Football League was founded in 1920, the National Hockey League was founded in 1917, and Major League Baseball was founded in 1869. Although MLS is relatively new, it is expanding almost every year, with more teams, games, fans, and exposure.

MLS is in a stage of rapid growth and seeks to expand into areas that are most marketable for soccer. Geographic information systems (GIS), which has tremendous potential to enhance leagues' business and marketing strategies, was underused for sports leagues. The use of GIS could provide specific answers to the critical questions: Where are the fans? Are there unique characteristics of the neighborhoods where fans live? 
Additionally, based on these neighborhoods, where might the league find similar neighborhoods with more potential fans? This project focused on addressing these important questions for MLS by conducting geographic analysis with GIS.

\subsection{Client}

Major League Soccer was the client for this project. The league was represented by Brett Lashbrook, Legal Counsel and Special Assistant to the Commissioner's Office. The client desired to know characteristics of MLS-supporting neighborhoods so the League could place new teams and stadiums in optimal locations. The League also desired to know where specific teams can market heavily and expect the best results. The League sought to have these questions answered through an initial experiment using GIS with a single club (team) as a sample: Los Angeles-based C.D. Chivas USA.

\subsection{Problem Statement}

MLS could detect clubs' success or lack of success simply by reviewing ticket/jersey sales and TV viewership. However, what was not clearly understood was in exactly what neighborhoods success was occurring. Without a clear knowledge of where and which kinds of neighborhoods MLS was succeeding in, it was difficult for the League's management to gauge what types of neighborhoods were more marketable for MLS.

\subsection{Proposed Solution}

GIS was proposed in this project to help MLS establish a concrete profile of MLSsupporting neighborhoods (based on measurable characteristics of where fans lived) and to find additional neighborhoods that likewise fit this profile. The outline of the project included importing the data MLS provided into a GIS, after which the data were 
combined with Esri's Business Analyst and Community Tapestry databases. These two datasets contain substantial demographic and income data (Miller, 2011) for census block groups (equivalent to a "neighborhood" for this project), and various community characteristics which were used to create the profile of MLS-supporting neighborhoods. With this profile, similar neighborhoods can be found where MLS could focus future marketing efforts and potentially recruit additional fans.

The error of ecological fallacy was avoided in this study, wherein inferences are made about individuals based on the groups to which they belong. Since the data provided by MLS does not contain any individual information except for the addresses, this study focused solely on neighborhoods, and characteristics of neighborhoods were examined. It did not make conclusions about individual fans. Individuals were used only for searching for the neighborhoods where soccer fans exist (i.e. some neighborhoods had Chivas USA season ticket holders while others did not).

\subsubsection{Goals and Objectives}

The first goal was to establish a neighborhood profile where MLS was more likely to be popular. The second goal was to identify similar, additional neighborhoods that fit the description of that profile. In doing so, answers were provided to the League's questions: where are MLS-supporting neighborhoods, what are these neighborhoods like, and where are there more neighborhoods like these?

\subsubsection{Scope}

The main objective of the project was to identify characteristics of neighborhoods where MLS fans reside. The analysis was primarily limited to season ticket holder data for the 
period of one season of one club. The data from other general MLS sales were also explored to substantiate and compare analysis from the season ticket holder data.

There were three main objectives to reach for these goals to be realized. First, cartographic products combined with written explanations to include tables and diagrams needed to be created. Second, a geodatabase needed to be created to store all the data digitally in a logical manner, which could then be used for further analysis beyond the scope of this particular project, if needed. This was imperative so that data were not lost, time was not wasted searching for data, and that work creating, storing, and updating data was not duplicated. Not only was the geodatabase greatly beneficial for this analysis, but it may yet prove valuable for a future project. Third, a GIS model, a system that processes data based on specified parameters, needed to be developed. Parameters could be input such as a specified drive time from a stadium, an ethnic profile, and an income profile, and the model would produce a map of highlighted areas that fit those parameters. The parameters in this project were based on the profile for the single club studied in this project, but the model could be adjustable for any club or season.

\subsubsection{Methods}

The project began after establishing contact with the client and determining their needs. ArcGIS 10 was determined to be the best software for conducting this project's GIS analysis. Using this software, a geodatabase was developed to store all of the data provided by the client, as well as any other data and tools which would be created or used throughout the project. An extensive literature review was conducted to determine which characteristics of neighborhoods should be examined. 
To conduct analysis of the client's data, additional data were needed. After reviewing available datasets, Esri's Business Analyst package was determined to be best suited for the client's issues because of its demographic information. Additionally, the Network Analyst extension was enabled to conduct travel cost analysis in ArcGIS 10. IBM's Statistical Package for the Social Sciences (SPSS) was used to analyze neighborhood data gleaned from Business Analyst and Network Analyst. SPSS's statistical outputs revealed numeric ranges which were used to create the marketable neighborhood profile.

A model was then developed within ArcGIS 10 which was designed to access data from Business Analyst and output results into the geodatabase. The model finds block groups in the Business Analyst data that fit the parameters of the profile. These parameters include income, ethnicity, and travel cost specifications. The model was stored in a toolbox within the geodatabase. The model can be adapted for other teams within Major League Soccer.

\subsection{Audience}

This project was designed for the highest levels of Major League Soccer's management. GIS is a recently-introduced technology to this audience, and the analysis has been documented with that fact in mind.

\subsection{Overview of the Rest of this Report}

Chapter 1 of this paper has been introductory. Background and literature review is discussed in chapter 2. Systems analysis and design is discussed in chapter 3. Database design is covered in chapter 4 . Chapter 5 discusses the results and analysis. Conclusions and Future Work are contained in Chapter 6. 



\section{Chapter 2 - Background and Literature Review}

For this study, two main topics of background research preceded the analysis. The first topic was the study of soccer in the United States and factors for marketability. The second topic was GIS applications in business with a specific focus on soccer. These two areas of background research provided a better understanding of a competitive, international industry which is expanding along with globalization. It likewise brought to light the power of GIS, which combines computer science, engineering, demography, and spatial statistics into a system with capability to greatly enhance the marketing strategy for a relatively new league.

\subsection{American Soccer and Marketability Factors}

Soccer popularity in the United States increased significantly in the 1970s when Brazilian soccer superstar Pelé came to play in MLS' predecessor, the North American Soccer League. Soccer's popularity in the country has continued to increase into the $21^{\text {st }}$ century. Kuper and Szymanski (2009) predicted the next phase of U.S. soccer through an examination of soccer growth and success across the globe by employing an exhaustive dataset of national soccer teams' match results spanning as far back as the $19^{\text {th }}$ century. Using this data, they measured international teams' match wins, ties, and losses with multiple variables to determine what makes countries successful in soccer. It was found that the most significant indicators that affect success of national teams were national population size, national GDP, and the country's years of experience in this sport. American soccer has the advantage with the first two indicators. Although the third indicator is not yet in America's favor, soccer still has the potential to expand in the 
country. Such expansion may benefit MLS because a national team's success can have significant positive external effects on the financial performance of domestic clubs and leagues (Ging, Hoffmann, \& Ramasamy, 2002).

The realization of America's soccer potential has already begun. According to the Sporting Goods Manufacturing Organization, the amount of teens playing baseball fell almost half (47\%) between 1987 and 2000. During that same period, however, youth soccer had been growing at an astronomical rate-by 2002, 1.3 million more kids played youth soccer than Little League Baseball (Foer, 2005).

It was, and is, critical for MLS clubs to find the most marketable neighborhoods to reach this new, emerging soccer generation. By working in optimal neighborhoods, clubs could pull in and retain loyal fans like Hornby (1998) who wrote that his love for his favorite soccer club had lasted "longer than any relationship [he] had made of his own free will" and that once he became a fan he was "chained" and there was "no way out". Such loyal fans help to sustain the development of soccer clubs. The importance of finding loyal fans (who attend matches) and retaining them was highlighted by Rick Parry, chief executive of the English Premier League in the 1990s who said, "You can change your job, you can change your wife, but you can't change your soccer team... you can move from one end of the country to another, but you never, ever lose your allegiance to your first team... it's about fierce loyalty, about dedication" (Eitzen, 2000, p. 16). These match-attending fans are also critical to obtain because their ticket purchases are the major source of income for most soccer clubs (Morrow, 2003).

The examples above are evidence that American soccer is on the rise and that MLS clubs needed to find fans who could be loyal customers. Season ticket holders and 
those who attend matches are the most loyal fans, also referred to as the "fanatical few" (Kuper \& Szymanski, 2009). However, the questions remained: where were the neighborhoods that season ticket holders lived in, what were the attributes of these neighborhoods, and where were there more neighborhoods with those same attributes? Additionally, which neighborhood attributes would be the most worth examining? Without answering these important questions, it is hard for the soccer industry to maintain a continuous development in the country.

\subsubsection{Relevant Determinants of Sport Attendance}

Research studies of attendance at professional sports matches have found that the general indicators that affect participation include ticket prices, travel costs, population, income, team quality, player quality, game conditions, competition from other sports or television, as well as the ethnic composition of a team and the fan base (Jewell \& Molina, 2005). High ticket prices, high travel costs, high competition, and uncomfortable match conditions have negative impacts on attendance. High regional populations, high team and player quality, and high similarity of team and fan base ethnicities have positive impacts on attendance. These indicators show how soccer is a 'representational' sport where fans of clubs represent specific communities (Bale, 2007).

While Kuper and Szymanski’s (2009) and Jewell and Molina’s (2005) broad range of regional indicators may have had some bearing on local marketing, these could certainly be studied at a finer geographic scale. Three of these major indicators, income, ethnicity, and travel cost, will be elaborated on in the following sections. These three indicators were selected because specific GIS data in these categories are available in Business Analyst. 


\subsubsection{Income}

Study of income is a consistent theme in sports marketing, and soccer has been called a "phenomenon of mass consumption" (Miller \& Crolley, 2007). Countries that have higher GNP, like Germany and Italy, have more success in international soccer competition than countries that have lower GNP, given other factors are the same (Ging, Hoffmann, \& Ramasamy, 2002). Similarly, regional income is an important factor for domestic club match attendance (Garcia \& Rodriguez, 2002). Sports leagues are businesses that rely on revenue for their existence, and some have claimed that soccer is indeed an industry and not a sport (Morris, 1981). All of this indicates that in the world of soccer, income matters. It is an important variable in international competition, club success, and match attendance. It drives the leagues.

Because MLS faces intense television competition from other sports leagues, they have a stronger dependence on gate revenue than other sports leagues (Jewell \& Molina, 2005). Major League Soccer, therefore, is very interested in learning who is currently attending matches, and how to increase attendance. Because income is one of the most important indicators of soccer attendance, it would be worthwhile to examine income characteristics of their fans' neighborhoods.

\subsubsection{Ethnicity}

In addition to income, ethnicity seems to be another important indicator for soccer success, as the sport may be more embedded and prevalent in certain ethnic regions (Ging, Hoffman, \& Ramasamy, 2002). The United States has been described as a "multicultural 'post-national' society" where soccer may be established in "niches" (Giulianotti, 1999, p. 169). One analysis showed that ethnicity is a significant indicator when 
examining the popularity of different sports (Downward \& Riordan, 2007). Hispanics in the United States have a long history of supporting soccer leagues in their home countries, and MLS assumed early on that establishing a fan base in this community could "guarantee long term success" (Jewell \& Molina, 2005, pp. 160-161). Early in the 2000 season, Mexican national soccer star Luis Hernandez came to play for the MLS in Los Angeles. In his home debut attendance boomed to over 40,000 fans, more than double the average of previous matches. Similarly, in Dallas, MLS earnestly reached out to its Salvadorian population, and despite MLS' overall attendance dropping from 1997 to 2000, Dallas' attendance increased each year in that time period (Jewell \& Molina, 2005, pp. 170-172).

The connection between sports popularity and certain ethnic neighborhoods can be studied in areas such as greater Los Angeles, which was described as a "natural laboratory for studying the residential patterns of immigrant groups in the American metropolis... [with the] extraordinary size and diversity of its immigrant populations" (Alba, Logan, \& Zhang, 2002, p. 302). It is expected that the popularity of a sport in an area has much to do with an area's ethnic groups.

\subsubsection{Travel Cost}

Travel cost was found to be another important indicator for attendance to matches (Jewell \& Molina, 2005). The likelihood of attendance increases when travel distance to a venue is shorter. The often used method for travel costs, known as the Clawson method, is a "trip generating equation" that involves surveying individual travelers to a location, placing them into zones, and then deducing consumer habits based on the zones (Common, 1973, p. 401). This method is subjective because researchers define zones 
and it can only yield ordinal measurements (Randall, 1994). The most recent publications on travel cost rely on statistical samples. For example, Barget and Gouget's (2007) sporting attendance study relied on surveys carried out inside a tennis stadium, and they believed that conclusions made using this methodology could only be "deliberative" at best. A soccer stadium study in Demark likewise relied on one sample of attendees to only one match (Kiil, Kjaer, \& Pedersen, 2010). Another handicap of previous methods has been the unavailability of detailed transportation data. For example, one study of soccer attendance used average car speeds gathered from the Department of Transportation which provided different averages for different areas, though the authors acknowledged that "the areas were not sharply defined" (Feehan, Forrest, \& Simmons, 2003).

Geographic information systems (GIS) contain remarkably intricate tools for study of match attendance, especially because of GIS' ability to calculate specific travel times and routes for travelers from hundreds of addresses to a stadium. Network analyses are "used to represent and analyze the cost, time, delivery, and accumulation of resources along links and between connected centers" (Bolstad, 2008, p. 362). One GIS study used a network analysis to determine the traveling potential for different ethnic and religious groups to greenspace (Brunsdon, Comber, \& Green, 2008); similarly a network analysis could be used to determine the traveling potential for different ethnic and income groups to a soccer stadium.

\subsection{Sports Marketing and GIS}

GIS has been widely used in the general business world for marketing purposes (Miller, 2011), but there are few reports of its application in the sports marketing area. Sports 
marketing is a growing field, and economists have recently begun taking a greater interest in sports, in part because soccer has become "a multi-billion dollar industry... generating huge revenues for private individuals, clubs, as well as national and international organizations" (Ging, Hoffmann, \& Ramasamy, 2002, p. 254). Smith (2005) identified the structural challenges for implementing GIS in a sports marketing company and concluded that it would have to be determined what department would employ the technology and how management would oversee it. The same study concluded that GIS could be used for marketing plans, targeting a market, and visualization.

There are several tools and datasets which could help sports marketing companies conduct research using GIS. Esri offers a business-tailored application called Business Analyst for its ArcGIS software. Business Analyst contains substantial demographic information about neighborhoods in the United States. Included is the Community Tapestry, which categorizes neighborhoods socioeconomically into 65 unique segments. Business Analyst data is meant to assist businesses in five key aspects of business planning. These include: Customer Market Analysis, Target Marketing and Campaign Planning, Store Market Analysis, Territory Design, and Customer Profiling and Prospecting (Miller, 2011).

\subsection{Summary}

American Soccer and Marketability Factors were first studied in the literature review. It documented the rise of soccer in the United States and predicted that as the national team continues to progress so should Major League Soccer. As the league grows and match attendance increases, several factors can influence what types of individuals and groups 
are more likely to attend. While multiple variables influence sports attendance, three key indicators for soccer attendance which are measurable with Business Analyst data are income, ethnicity, and travel cost. Specific income ranges, high Hispanic percentages, and low travel cost neighborhoods should be most marketable for soccer. Neighborhoods that fit these three criteria are the best candidates for Major League Soccer's marketing strategies.

The second topic studied was Sports Marketing and GIS. There is a wellestablished relationship between Business and GIS. However, GIS has yet to be widely implemented in the sports marketing business. GIS can be utilized in this field by helping in planning, visualizing, and decision-making. Business Analyst, with its large demographic datasets and Community Tapestry, could be an excellent resource for sports marketing. GIS has the potential to significantly enhance sports marketing strategies. 


\section{Chapter 3 - Project Plan}

This project required a plan which was centered on the need for a GIS model, built with parameters for marketability. The model would search for neighborhoods that contained the ranges of these parameters. The newly identified neighborhoods would answer the client's primary questions and reveal neighborhoods where the club would be most marketable.

\subsection{Problem Statement}

MLS wanted to know what kind of neighborhoods their fans resided in, and where they could find more neighborhoods like these. This information would enhance their marketing strategy. MLS wanted to use a single club for a preliminary analysis, for their first endeavor with GIS. The club MLS chose was Chivas USA, a Los Angeles-based team.

\subsection{Requirements Analysis}

GIS pioneer Roger Tomlinson noted that "getting the system requirements right at the onset is what separates the adults from the children in successful GIS planning"

(Tomlinson, 2007). With this observation in mind, the requirements analysis was divided into four sub-categories: functional, technical, operational, and transitional (Table 1).

\section{Table 1. Requirements Analysis Overview.}

\begin{tabular}{|c|c|c|c|}
\hline $\begin{array}{l}\text { Functional } \\
\text { Requirements }\end{array}$ & $\begin{array}{l}\text { Technical } \\
\text { Requirements }\end{array}$ & $\begin{array}{l}\text { Operational } \\
\text { Requirements }\end{array}$ & $\begin{array}{l}\text { Transitional } \\
\text { Requirements }\end{array}$ \\
\hline $\begin{array}{l}\text { Profile of } \\
\text { marketable } \\
\text { neighborhoods, } \\
\text { digital maps }\end{array}$ & $\begin{array}{l}\text { Software: ArcGIS, } \\
\text { Microsoft Word and } \\
\text { Excel, SPSS; } \\
\text { software licenses }\end{array}$ & $\begin{array}{l}\text { Geoprocessing } \\
\text { tools: Geocode, } \\
\text { Intersect, Select, } \\
\text { Network Analyst }\end{array}$ & $\begin{array}{l}\text { Microsoft Excel } \\
\text { spreadsheet table } \\
\text { into GIS, geocode } \\
\text { addresses }\end{array}$ \\
\hline
\end{tabular}


Functional requirements in this project comprised both the goals and deliverables of the project. These included the profile of marketable neighborhoods, as well as digital maps displaying details of the profile. Technical requirements specified the software needed to conduct the analysis and complete the project report, which included ArcGIS (for GIS analysis), SPSS (for statistical analysis), and Microsoft Word (for documentation). Operational requirements were concerned with the geoprocessing operations needed for processing and analyzing the data. The major geoprocessing functions used in the project included geocoding, intersecting, selecting, and various geoprocessing functions of network analysis. Transitional requirements for this project referred to converting the data from their original Microsoft Excel format to the format that can be edited in ArcGIS. These requirements were addressed at the onset of the project and ensured that the analysis proceeded smoothly.

\subsection{Project Workflow}

The system design for this study entailed a workflow with eight major steps (Figure 3-1).

First, the problem was clearly established and documented. Second, the data were acquired and organized into a geodatabase. The data were first provided as Microsoft Excel spreadsheets (from Chivas) and text files (from MLS), as lists of addresses, and were then stored in the geodatabase. These data were geocoded and Esri's Community Tapestries were studied to learn more about the Chivas neighborhoods and find variables

they had in common. Third, the incomes of the fans' neighborhoods were analyzed. This was conducted using Esri's Business Analyst datasets, which contain extensive demographic information for individual U.S. Census block groups. Fourth, the ethnic 
layout of the fans' neighborhoods was established. This was also conducted using Business Analyst data.

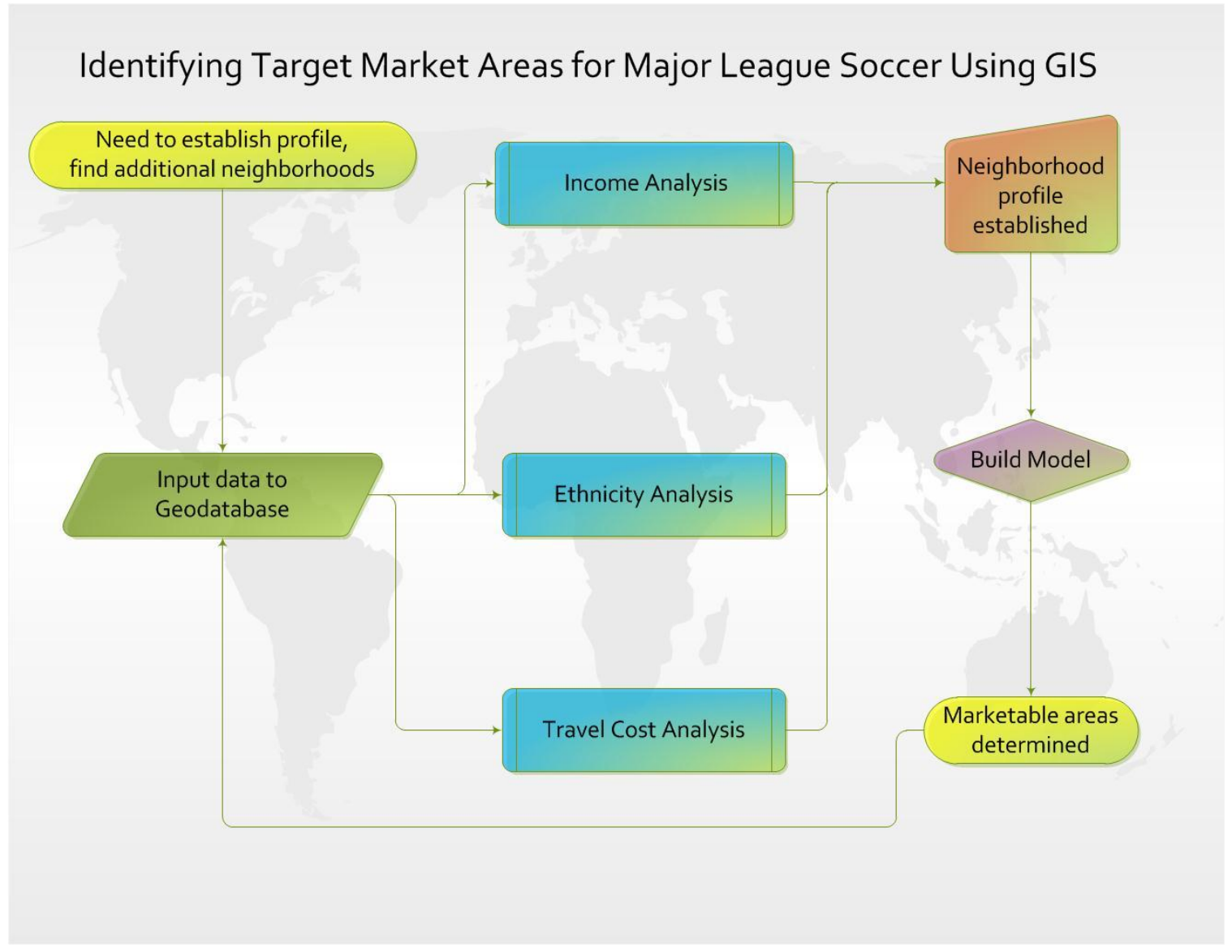

Figure 3-1: System Design

Fifth, the drive times from the season ticket holders' addresses to the stadium under consideration were calculated on the street network and further analyzed to estimate the driving time range for fans to travel to soccer matches. Sixth, the criteria from steps three through five were combined to establish the neighborhood profile. Seventh, a GIS model was created with parameters based on the profile. Eighth, using the model from step seven, marketable areas was determined. The end result was maps showing areas in southern California that fit all the criteria of the profile. These maps showed the client in what neighborhoods they could probably have more success in 
marketing efforts. The new marketable areas were compared with the original Chivas neighborhoods to determine the extent of overlap, and to see how many new neighborhoods were discovered.

One element of the study which was more complex than anticipated was determining what variables to use for marketability. Business Analyst contains hundreds of variables, each of which could be studied as characteristics of neighborhoods. The background literature review was tremendously important for narrowing these down. The literature review revealed approximately eight major variables influencing soccer match attendance and three of these were used for this study: income, ethnicity, and travel cost.

In summary, the system design included a workflow with GIS and other software functions to determine characteristics of neighborhoods where fans lived. Then, using these characteristics, similar neighborhoods were identified.

\subsection{Modifications}

Major adjustments and enhancement to the analysis involved conducting a comparative analysis for the findings obtained from the Chivas data. Specifically, a second set of data, which encompassed all MLS sales from 2007 to 2010 including SUM (Soccer United Marketing) Ticketmaster, MLS E-Newsletter subscriptions, Grassroots events (Futbolito, Sueno, etc.) and MLS Sweepstakes, was analyzed. This was instructive, showing how Chivas neighborhoods were distinct from neighborhoods that supported the league in general. Comparisons were also made among the Chivas neighborhoods and the general population of southern California. 


\subsection{Summary}

Major League Soccer needed to learn where neighborhoods were that could be most marketable for their clubs. They selected Chivas USA for a preliminary analysis using GIS. To accomplish this, the GIS analyst used ArcGIS, as well as Microsoft Office and SPSS. Operating on a pre-planned timeline, GIS analysis was conducted to determine what ranges should be used for a marketability study. Once this was determined, a model was built which could identify these areas. The areas were discovered using the model to the satisfaction of Chivas USA and MLS. 



\section{Chapter 4 - Database Design}

This project involved the acquisition and analysis of spatial data. Season ticket sales and other data were provided by Chivas USA and Major League Soccer. Before analyzing the ticket sales, a geodatabase was developed to store all of the data. A geodatabase is defined as "a collection of geographic datasets stored using a database management system or file system" (Zeiler, 1999, p. 8). Storing the data in the geodatabase helped organize it in a logical way such that data access and data query became much more efficient.

\subsection{Conceptual Data Model}

The concept for the data and analysis of this project can be visualized in a UML diagram (Figure 4-1). The core object in the model is season ticket holder addresses from Chivas USA. Point density, standard deviational ellipse, and mean center are derived from this object. The secondary object is the U.S. Census block groups (provided in Esri's Business Analyst package). Season ticket holders live in or do not live in individual block groups. Some block groups share similar ethnicity and income characteristics to Chivas block groups. Chivas USA is most marketable for these similar block groups. 


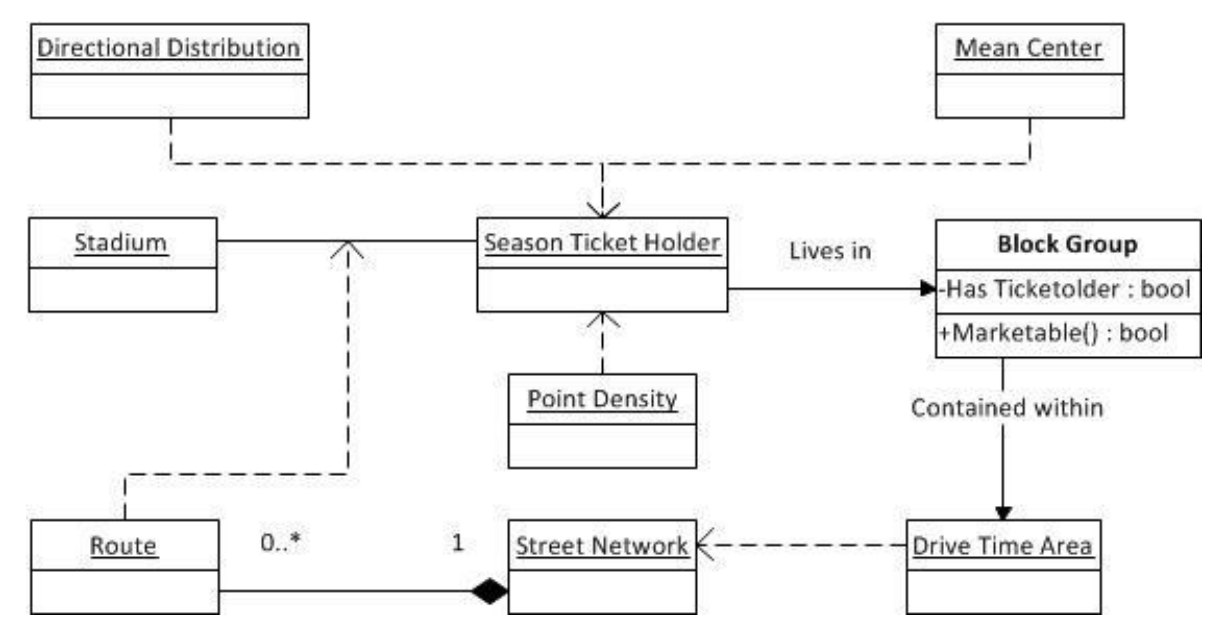

\section{Figure 4-1: Conceptual Data Model}

The remaining objects are related to travel cost. Multiple routes from season ticket holder addresses to the stadium are derived from one street network available in Esri's Business Analyst package. The drive time areas where Chivas is marketable are derived from the street network.

\subsection{Logical Data Model}

In designing the geodatabase, the layout was kept as simple as possible, whereby it might be used by multiple users if ever necessary (this was also accomplished by creating a file geodatabase which could be accessed by many, as opposed to a personal geodatabase which could only be accessed by one). The decision was made to store the data in the geodatabase in subcategories of the GIS' basic entities: lines, points, polygons, and raster.

\subsubsection{Lines}

The Lines feature dataset contains all data associated with the travel cost analysis (Figure 4-2). The SoCal_Highways feature class contains all major highways in southern California. The Chivas_DriveTimes feature class contains drive times to the stadium, and the SoCal_DriveTimes feature class contains the time for each block group in 
southern California. The Chivas_DriveRoutes feature class contains the shortest (drive time) route for each season ticket holder to the Home Depot Center, and the SoCal_DriveRoutes contains the shortest route for each block group in southern California.

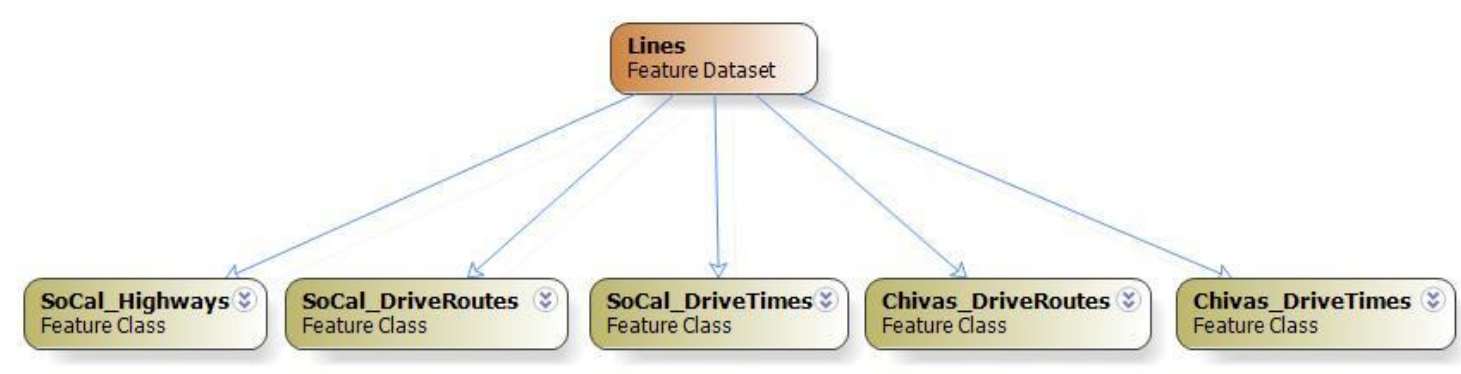

Figure 4-2: Lines Feature Dataset

\subsubsection{Points}

The Points feature dataset contains data critical to several analysis categories (Figure 4-

3). The Chivas_Addresses feature class contains all of the season ticket holder addresses after being geocoded (plotted) into the GIS; the MLS customer data are contained in MLS_Addresses, and centroids of each block group in southern California are contained in SoCal_Neighborhood_Points. Mean centers, used to find the geographic center of all data, are contained in Chivas_MeanCenter (for the Chivas addresses), MLS_MeanCenter (for the MLS data), and SoCal_MeanCenter (for all of southern California). The Home_Depot_Center feature class contains Chivas USA's home stadium. 


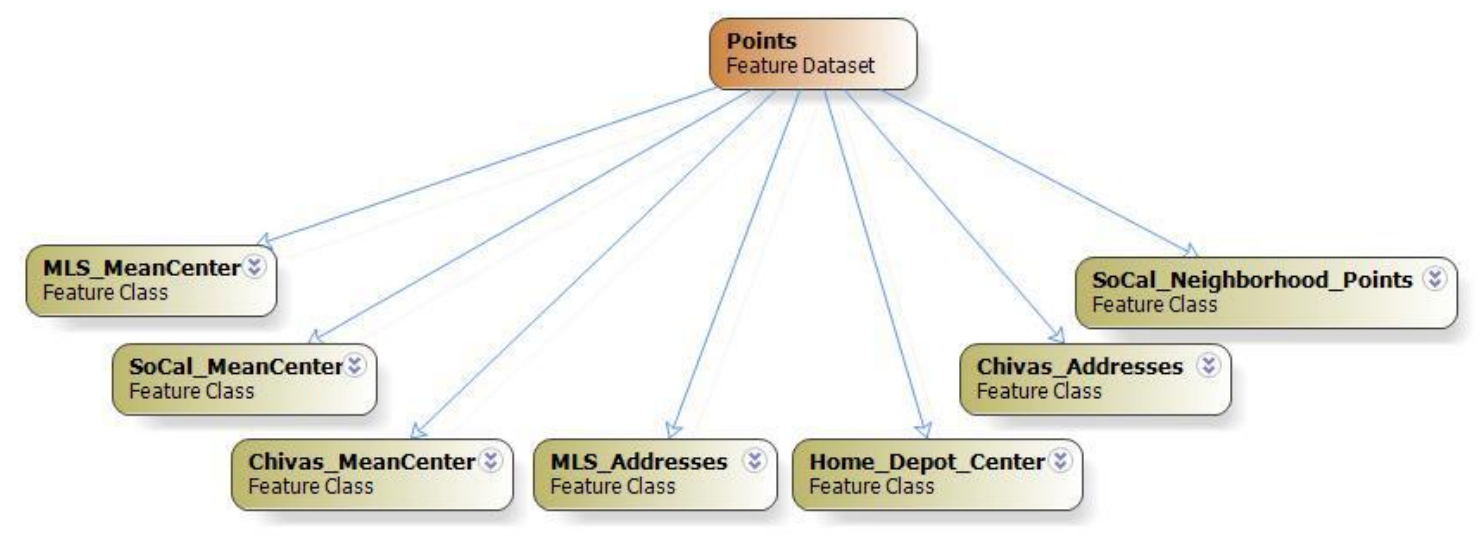

Figure 4-3: Points Feature Dataset

\subsubsection{Polygons}

The Polygons feature dataset also contains data critical to several categories of analysis

(Figure 4-4). The Chivas_Neighborhoods feature class contains all block groups with

Chivas season ticket holders residing in them. SoCal_Counties and

SoCal_Neighborhoods contain the counties and block groups in southern California.

Directional distribution, which displays an ellipse of one standard deviation away from

the mean center, are contained in Chivas_DirectionalDistrib for Chivas,

SoCal_DirectionalDistrib for all southern California neighborhoods, and

MLS_DirectionalDistrib for the MLS data. The drive time areas for the travel cost analysis are also contained in this feature dataset. The median drive time areas for Chivas and all southern California can be found in Chivas_MedianDriveTime and SoCal_MedianDriveTime. The $75^{\text {th }}$ percentile drive time areas can be found in Chivas_75PercDriveTime and SoCal_75PercDriveTime. 


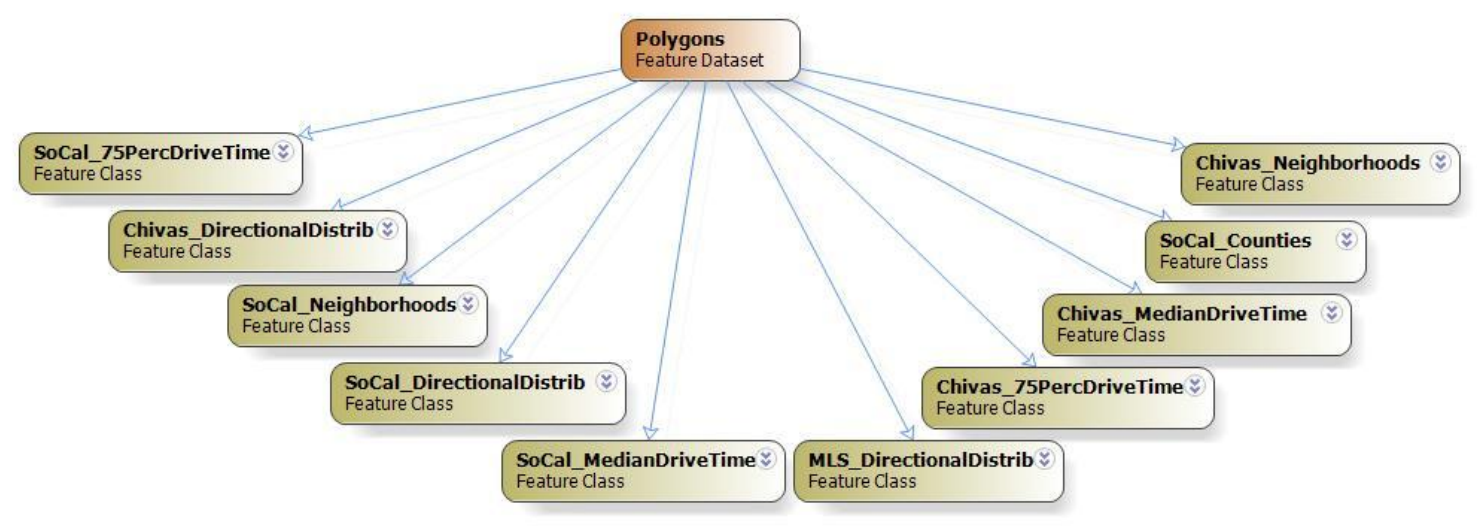

Figure 4-4: Polygons Feature Dataset

\subsubsection{Raster Datasets, Toolbox, and Marketability Feature Dataset}

The geodatabase also contains three raster datasets resulting from the point density analyses: Chivas_Point Density (for Chivas season ticket holder addresses),

SoCal_PointDensity (for all neighborhoods in southern California), and MLS_PointDensity (for all MLS customers in southern California).

A toolbox was created called Marketability_Models in the geodatabase to contain the model called MLS_Marketability. The model was designed to output all new feature classes to a feature dataset called Marketability. When the model is run using the median drive time, a feature class called Marketable is created, and when it is run using the extended $75^{\text {th }}$ percentile drive time, a feature class called Marketbale_extend is created.

The geodatabase's design and implementation went forward with these basic layouts, and successfully maintained its simplicity throughout the project. The data from all maps in this report are stored in the geodatabase.

\subsection{Data Sources}

All data in this project came from one of three main sources: (1) C.D. Chivas USA and MLS, (2) Esri Business Analyst, or (3) the outputs from the geoprocessing functions. 
The season ticket addresses for the 2010 season were provided by Chivas USA, which were then geocoded. The MLS data were provided by the league and likewise geocoded. The Esri BA data were analyzed with the Chivas and MLS data. The analysis produced the remainder of the data which were created from geoprocessing functions, all of which were combinations or comparisons of data from the first two sources.

\subsection{Data Scrubbing and Loading}

The address data, provided by Chivas USA in the form of a Microsoft Excel spreadsheet, was in a compatible format for input into ArcGIS, except for a few spelling errors of addresses which were fixed manually using ArcGIS' geocoding service, as well as some PO Box addresses which could not be used. The MLS addresses were provided in a text file which was first transformed into a spreadsheet, then geocoded in the same manner as the Chivas data. The Business Analyst data were substantial, and only necessary data were accessed in order to remain within the scope of the project.

\subsection{Summary}

The data in this project were provided by Chivas USA, Major League Soccer, and Esri's Business Analyst. Additional data were created by using ArcGIS. Almost all of the data were stored in the project's geodatabase, which was designed with the principles of simplicity and shared accessibility. 


\section{Chapter 5 - Results and Analysis}

The analysis of marketable neighborhoods for Chivas consisted of two main steps. First, the profiles of the neighborhoods where season ticket holders resided were established. The characteristics of these neighborhoods were first analyzed using Esri's Community Tapestry which describes different categories of neighborhoods in the United States. Three variables — income, ethnicity, and travel cost—were used in describing neighborhood profiles. Further analysis was conducted with each of these variables to quantify the profiles of marketable neighborhoods. The second major step focused on identifying additional neighborhoods which fit the determined profile.

\subsection{Defining the Profile}

Before establishing specific ranges for each of the three variables to construct the neighborhood profile, a preliminary analysis was conducted which examined the general spatial pattern of season ticket holders as well as Esri’s Community Tapestry.

The factors that affect whether a neighborhood is marketable for soccer teams probably change from team to team, from region to region, and from league to league. This study focused on a single club, Chivas USA, for a single season, and can serve as a starting point for future analyses with different data for other teams and leagues. Seasonal variations in marketable neighborhoods were not studied because there was little change in season ticket holders from season to season. For example, Chivas reached 90\% renewals with their season ticket holders between 2009 and 2010.

A second dataset of all MLS customers in southern California was also analyzed to compare with the results obtained from the Chivas dataset. This dataset encompassed 
all MLS sales from 2007 to 2010, and included sales from SUM's (Soccer United Marketing) Ticketmaster purchases, MLS E-Newsletter subscriptions, Grassroots events (Futbolito, Sueno, etc.), and MLS Sweepstakes. There were 364 customers in Chivas' dataset and 39,499 in MLS's dataset.

For this project, census block groups were used to define neighborhoods for Chivas' dataset. This was due to the fact that the most useful demographic data used in the study are available at this aggregation level. The MLS data only contained zip codes for addresses, so zip code boundaries were used as neighborhoods for this dataset. Each neighborhood in the analysis was weighted by the number of fans living within it. This was accomplished by duplicating a neighborhood's data for every additional fan living within its boundaries (e.g. a neighborhood with an average $\$ 10,000$ income has two season ticket holders living in it, therefore the $\$ 10,000$ value is used twice when calculating the median income of all neighborhoods). Such duplication is rare for the Chivas data: of all the block groups with Chivas fans residing in them, only one contained more than two fans. Since the MLS customer data cover four years, it was much larger and thus had more duplications.

\subsubsection{Spatial Patterns of Ticket Holders and Associated Neighborhoods}

The first step was to geocode the season ticket holder addresses (Figure 5-1). The geocoded addresses showed how the fans' addresses are distributed throughout the southern California region. However, further analysis was needed to determine whether this distribution was merely mirroring the general population, or if the Chivas distribution was unique. The MLS data was also examined to determine if there any differences between Chivas fans and general MLS fans. 


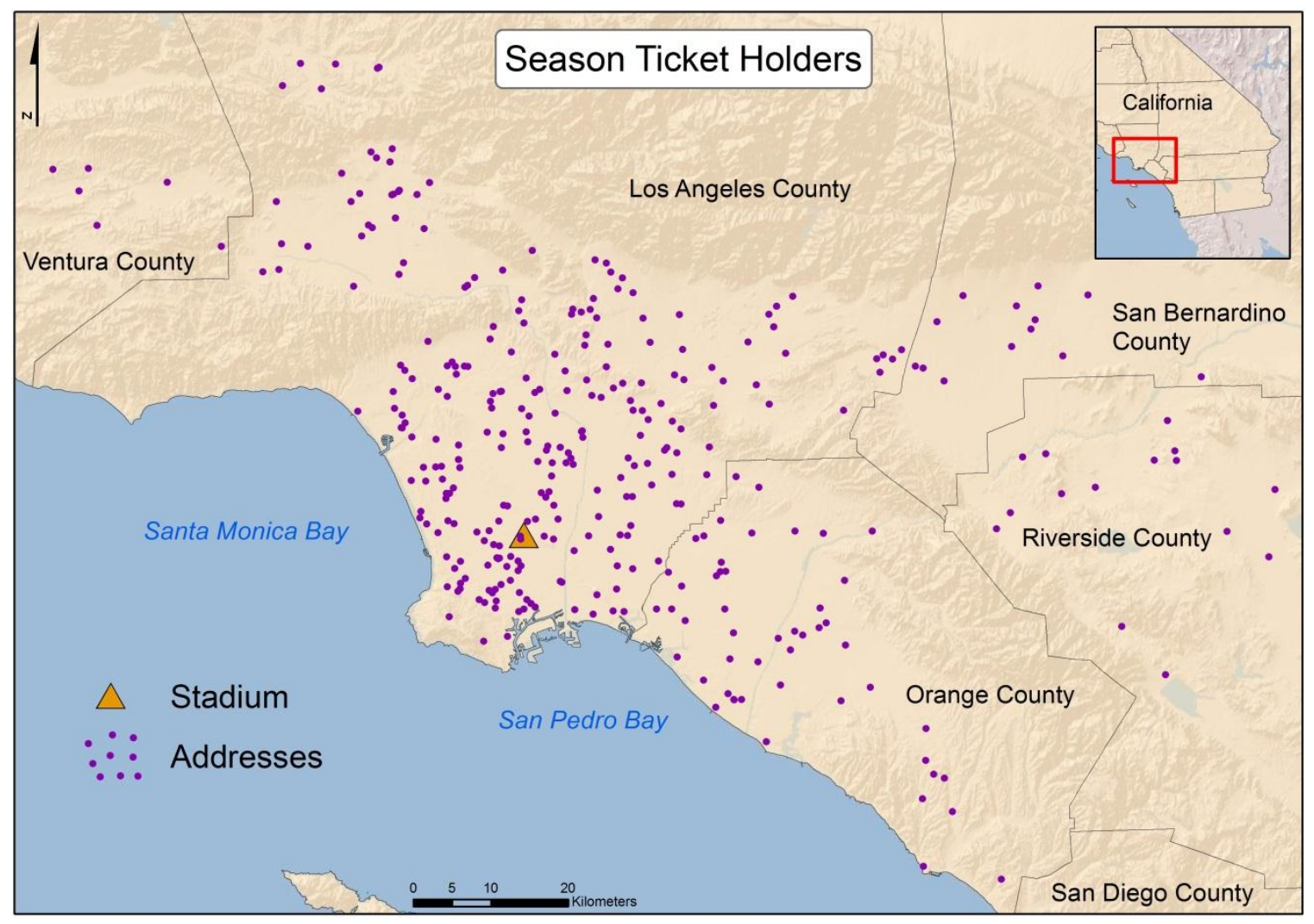

Figure 5-1: Addresses of Chivas Season Ticket Holders

With the addresses geocoded, a point density map, often referred to as a heat map, of these individual ticket holders was generated (Figure 5-2). A point density map helps to visualize the hotspots of a point dataset. Figure 5-2 displays the distribution of fans for the Chivas team, where three main clusters can be observed: one in the northwest in the San Fernando Valley, one southeast of Downtown Los Angeles, and one in the South Bay near the club's stadium in Carson. 


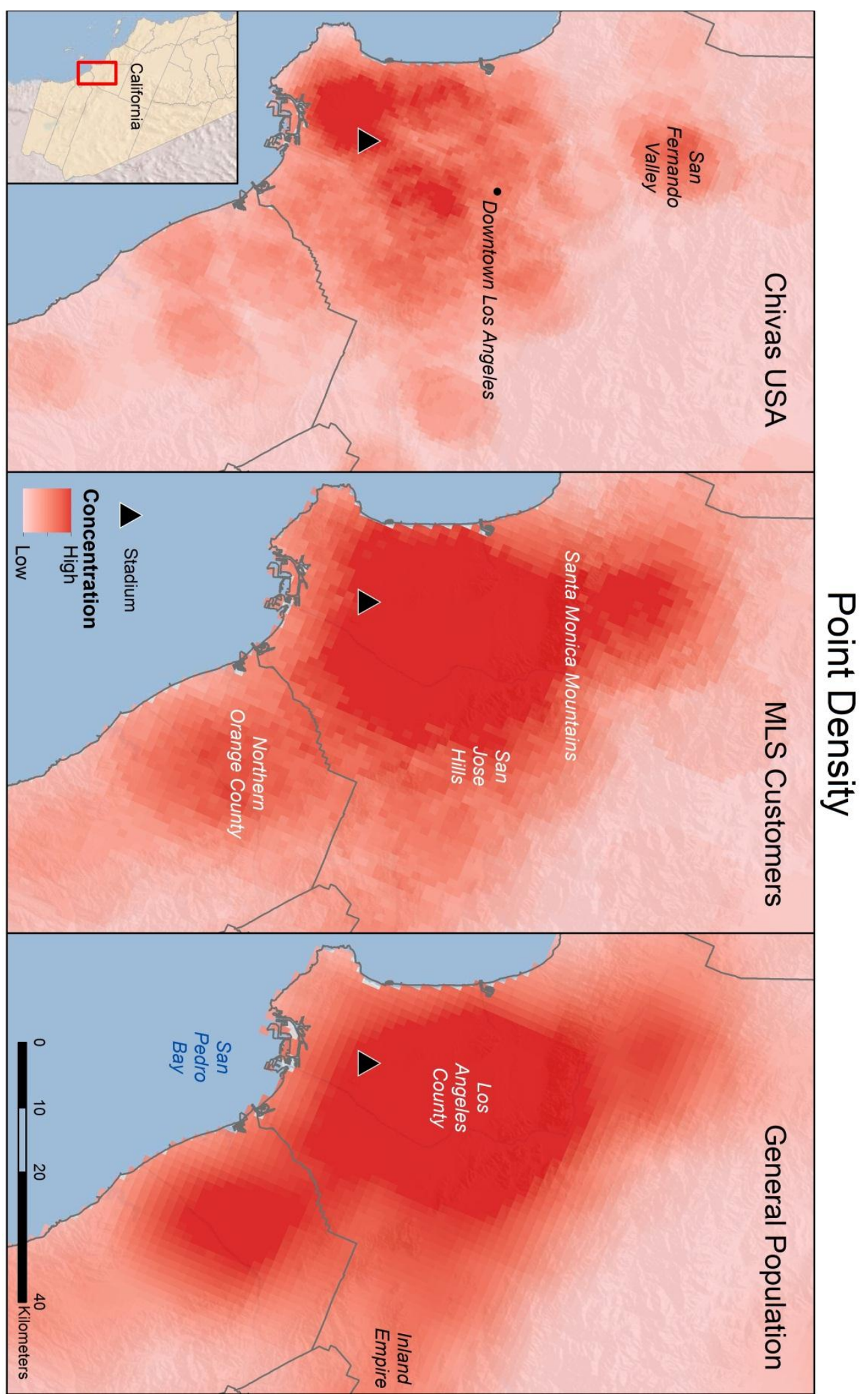

Figure 5-2: Point Density 
Figure 5-2 also shows the point density of the sales for MLS. The strongest cluster occurs in the Los Angeles Basin (this includes all of Los Angeles County south of the Santa Monica Mountains and west of the San Jose Hills). There are some less prominent clusters in the San Fernando Valley, northern Orange County, and to a lesser extent, the Inland Empire (western populated areas of San Bernardino and Riverside Counties). Compared to the spatial pattern of Chivas season ticket holders, the spatial pattern of the MLS sales appear to better match the overall general population. This might be because the fan base of MLS is much larger and more diverse than that of Chivas.

To further examine the spatial distributions of Chivas fans, MLS fans, and the general population, the mean center and directional deviation ellipse were also generated for all three datasets (Figure 5-3). The mean centers are the geographic center of all data. The center of Chivas' ticket sales is located in Commerce, California, where 95\% of the population is Hispanic. Compared to the mean center of Chivas' ticket holders, the mean center of MLS customers moved to the southeast and was located in Fullerton which has a lower Hispanic population percentage (34\%) than Commerce. The general population's mean center was close to the MLS', in Anaheim, which suggests that MLS customers are more similar to the general population, whereas Chivas is more unique from the general population. 


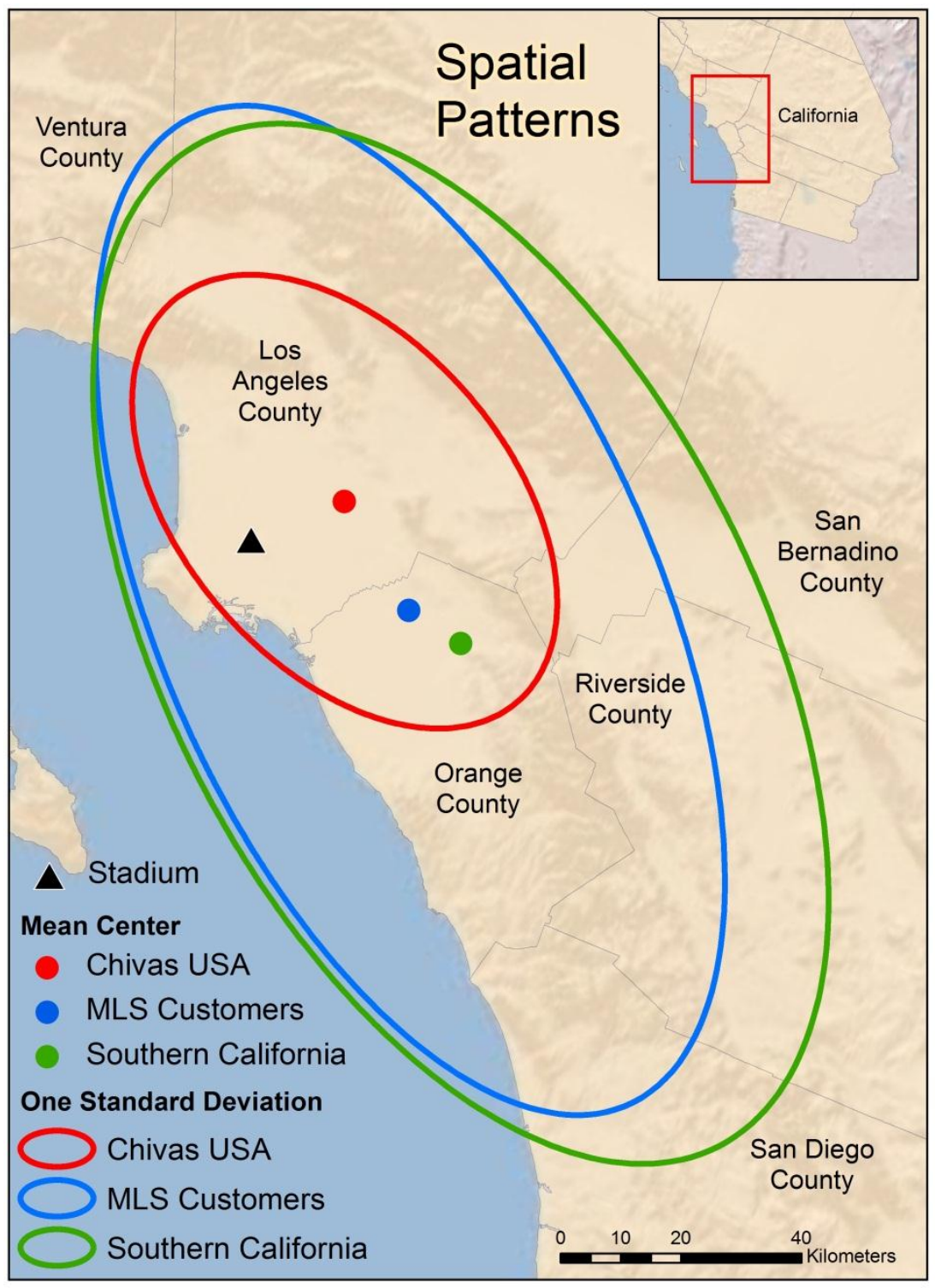

Figure 5-3: General Spatial Pattern

The directional deviation ellipse indicates the central tendency, dispersion, and directional trends. It seems that the greater portion of Chivas fans live within the Los Angeles Basin, with a sizable amount also residing in the San Fernando Valley and northern Orange County. The deviational distribution of the MLS dataset extended comparatively more to the southeast, reaching San Diego County, aligning fairly well with the ellipse of the general population. This again seems to indicate that MLS has a 
broader appeal to the general population than does Chivas, which has garnered a more specific and unique following.

In general, the basic spatial descriptive statistics, including mean center and standard deviational ellipse, suggest that Chivas USA could concentrate their marketing efforts in southern Los Angeles County and northern Orange County, emphasizing three major areas (the San Fernando Valley, the region southeast of Downtown Los Angeles, and the South Bay). Another important fact realized in this analysis was the importance of proximity; the most prominent cluster of fans was circulated around the stadium. This suggests the importance of travel distance for the neighborhood profile, which coroborates the findings in the literature as discussed in Chapter 2.

\subsubsection{Neighborhood Profiles Obtained from Community Tapestry}

Esri's Community Tapestry dataset was used to analyze the characteristics of the neighborhoods where ticket holders resided. This dataset was provided through Esri's Business Analyst and classifies neighborhoods into segments which are "classifications of U.S. neighborhoods into 65 distinct lifestyle clusters based on factors such as age, income, education, housing, purchasing patterns, and values" (Miller, 2011, p. 26). Each geocoded address was contained in one of these segments. Thirty-nine of the 65 segments were represented in the Chivas addresses. Of these 39 segments, two stood out among all the rest in frequency (Table 2). All segment names and their descriptions are taken directly from Esri's Community Tapestry guide. 
Table 2. Neighborhoods Represented in Chivas USA Data

\begin{tabular}{|l|r|l|r|}
\hline Tapestry Segment Name & Count & Tapestry Segment Name & Count \\
\hline Las Casas & 62 & Prosperous Empty Nesters & 3 \\
\hline Urban Villages & 49 & Sophisticated Squires & 3 \\
\hline Pacific Heights & 27 & Young and Restless & 3 \\
\hline Connoisseurs & 22 & Boomburbs & 2 \\
\hline International Marketplace & 21 & Dorms to Diplomas & 2 \\
\hline Trendsetters & 16 & Exurbanites & 2 \\
\hline Urban Chic & 14 & Family Foundations & 2 \\
\hline NeWest Residents & 13 & Milk and Cookies & 2 \\
\hline Laptops and Lattes & 12 & Social Security Set & 2 \\
\hline Pleasant-Ville & 11 & Unclassified & 2 \\
\hline Wealthy Seaboard Suburbs & 10 & Cozy and Comfortable & 1 \\
\hline Top Rung & 8 & Crossroads & 1 \\
\hline Industrious Urban Fringe & 7 & Green Acres & 1 \\
\hline Inner City Tenants & 6 & Main Street USA & 1 \\
\hline Aspiring Young Families & 5 & Midland Crowd & 1 \\
\hline City Lights & 4 & Modest Income Homes & 1 \\
\hline Enterprising Professionals & 4 & Senior Sun Seekers & 1 \\
\hline Suburban Splendor & 4 & Silver and Gold & 1 \\
\hline Up and Coming Families & 4 & Simple Living & 1 \\
\hline Urban Melting Pot & 4 & \\
\hline & & \\
\hline
\end{tabular}

The two most frequent segments were "Las Casas" and "Urban Villages" (Figure 5-4). Together these two segments comprised more than a third of all neighborhoods represented in the Chivas dataset (111 out of 335). These two were also the two top ranked in the MLS data, further suggesting that these two segments have a relationship with soccer. Full descriptions of Las Casas and Urban Villages from Esri's Tapestry Segmentation Reference Guide are given in Appendix A. There is one major commonality between these two neighborhoods: both have majority Hispanic populations (Las Casas 84\%, and Urban Villages 61\%). In addition, Las Casas residents "watch and play soccer" and Urban Village residents "take vacations in Mexico." These 
characteristics further confirmed the fact that percentage of Hispanics in a neighborhood may influence its residents' preference for Chivas USA.

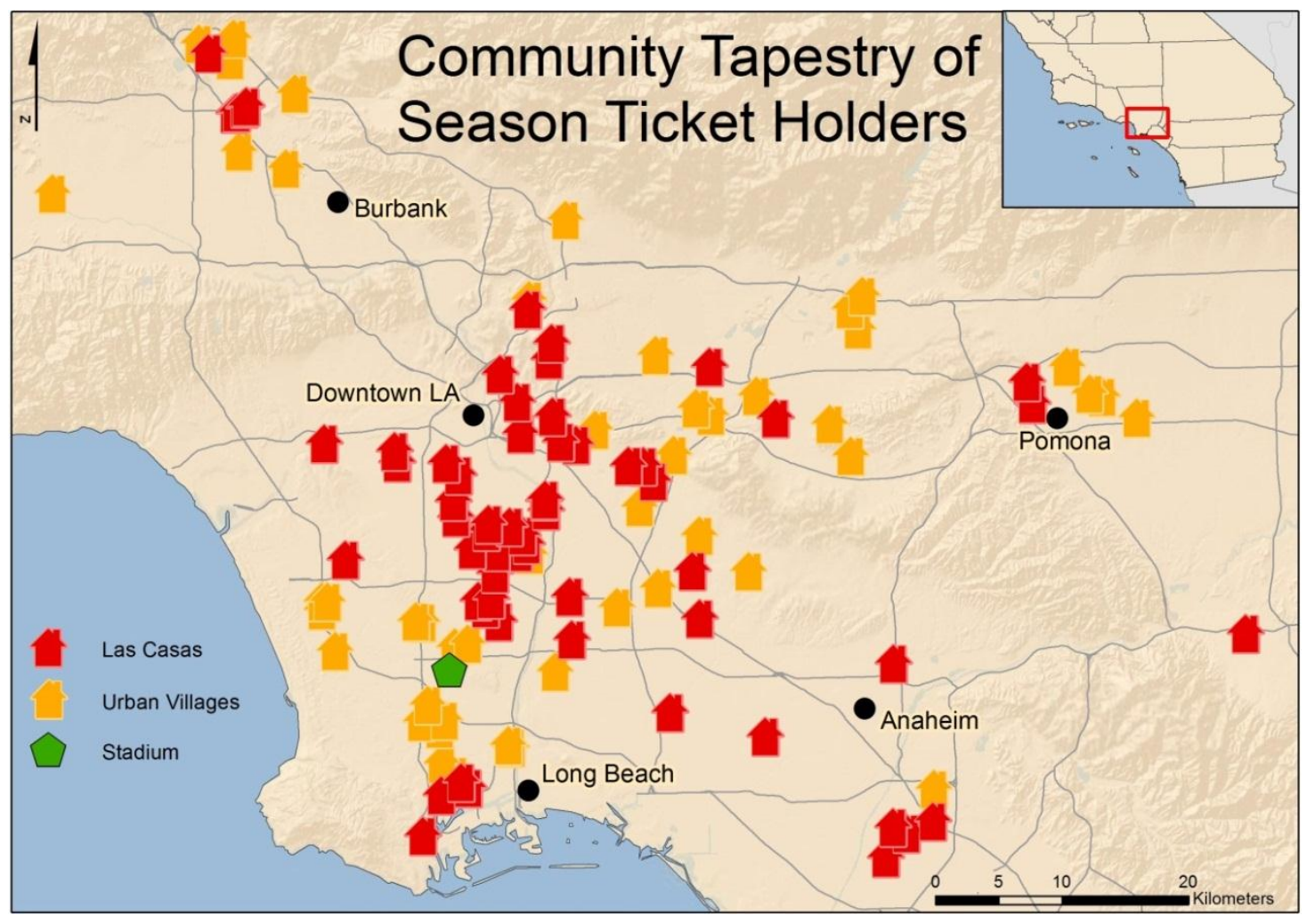

Figure 5-4: Chivas Community Tapestries Map

Further, location quotients of the frequencies of these two neighborhoods were calculated to determine the relative dominance of these neighborhoods for Chivas when compared to all neighborhoods in southern California. Location quotient is a commonly used measurement for industry specialization. It is calculated as a ratio between the percentage of an industry in a local area, such as a city, and the percentage of that industry in a reference area like a county. If the ratio is greater than 1 , the industry is regarded as specialized in the local area. In this study, the reference area was chosen to be all neighborhoods in Southern California, as this would help to determine whether the dominance of the particular neighborhoods for Chivas was actually due to the dominance 
of these neighborhoods in Southern California. The location quotient results are listed in Table 3.

Table 3. Community Tapestry Location Quotients

\begin{tabular}{|l|l|l|l|}
\hline & $\begin{array}{l}\text { Percentage in } \\
\text { Chivas } \\
\text { Neighborhoods }\end{array}$ & $\begin{array}{l}\text { Percentage in } \\
\text { Southern California } \\
\text { Neighborhoods }\end{array}$ & $\begin{array}{l}\text { Location Quotient } \\
\text { Value }\end{array}$ \\
\hline $\begin{array}{l}\text { Urban Villages and } \\
\text { Las Casas }\end{array}$ & $33 \%$ & $22 \%$ & 1.5 \\
\hline
\end{tabular}

The results show that Las Casas and Urban Villages are overrepresented in the Chivas neighborhoods when compared to the general population of southern California. The confirmed specialization of these neighborhoods validated their characteristics as possible indicators of marketability. However, because these neighborhoods comprised only a third of all the neighborhoods, more variables needed to be studied in greater detail.

It is also important to note two segments that were not included in the Chivas neighborhoods: Rural Bypasses and Heartland Communities. These two segments were selected because of their characterizations in non-soccer sports recreation and the following descriptions are taken from Esri's official Tapestry descriptions (Appendix A). Rural Bypasses have much “open space and farmland” and are 58\% White and 36\% Black. They are small towns with a country lifestyle, where residents listen to country music and watch NASCAR. Heartland Communities are 90\% White and half the residents are retired. They are described as being settled and close-knit where residents hunt, fish, and watch the news. This finding suggests the popularity of a specific sport may be spatially dependent, and searching for appropriate neighborhoods is very important for sports marking. The following sections will examine the neighborhood 
characteristics of Chivas' ticket holders by considering neighborhood income level, population ethnicity, and travel cost to the stadium.

\subsubsection{Income}

The goal in studying income was to determine the income range of the most marketable neighborhoods based on the neighborhoods where season ticket holders resided. This range would then be incorporated into the neighborhood profile. The Business Analyst data showed that higher per capita incomes could be found in both suburban coastal and suburban foothill areas (Figure 5-5). Most of the Chivas neighborhoods were inland, away from the coastal or foothill areas and where incomes were relatively lower.

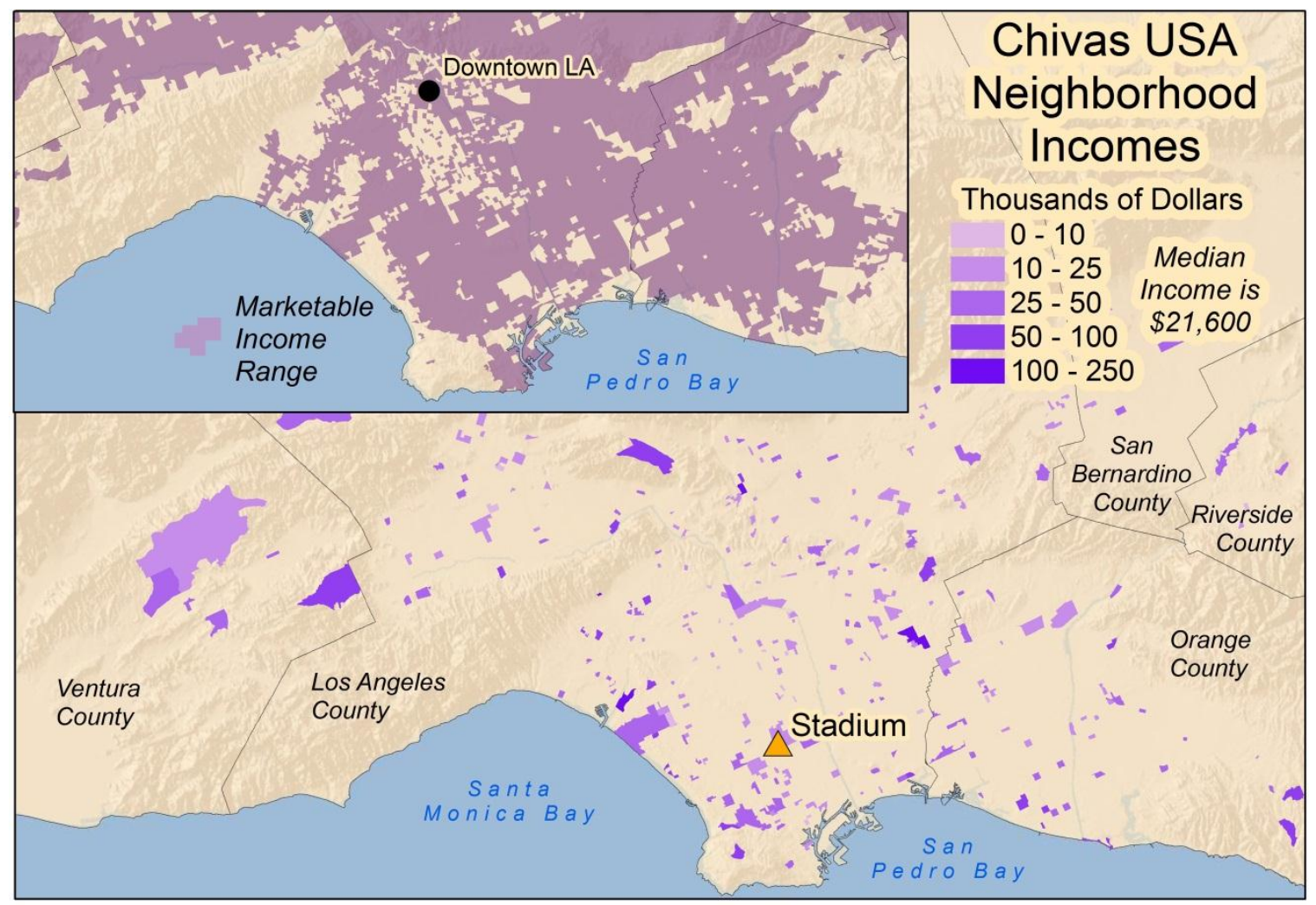

Figure 5-5: Chivas Neighborhoods Income Map

While most of the season-ticket holders lived in the lower-income areas, there was also a distinct conglomeration of higher-income areas, ranging along the Santa 
Monica Bay coastline. If the club's strategy is to seek sheer quantity of fans they might market in the Los Angeles Basin or San Fernando Valley, away from the coastal and foothill areas. However, if the club's strategy is to seek higher income neighborhoods, they might market in the coastal areas.

Further analysis showed that, rounded to the nearest hundred, the median income was $\$ 21,600$. This amount represented the average neighborhood income of the neighborhoods where season ticket holders were found. To establish a range for the profile, a $75^{\text {th }}$ percentile range was taken from this median value. As with the other characteristics, using a $75^{\text {th }}$ percentile remained the consistent methodology for establishing a range, and this variable's was $\$ 10,000-\$ 44,000$.

To determine the implications of this range, the same analysis was conducted with the MLS data and the general population (Figure 5-6). The median value from each of these datasets was determined: $\$ 22,100$ for MLS neighborhoods and $\$ 22,800$ for overall neighborhoods in southern California. Because the average Chivas neighborhood income was lower than the MLS neighborhoods in the region, it may indicate that less affluent neighborhoods are supporting Chivas and comparatively higher income neighborhoods are supporting the other MLS team in the area, the Los Angeles Galaxy. It is very likely that teams other than Chivas would have substantially different medians. 

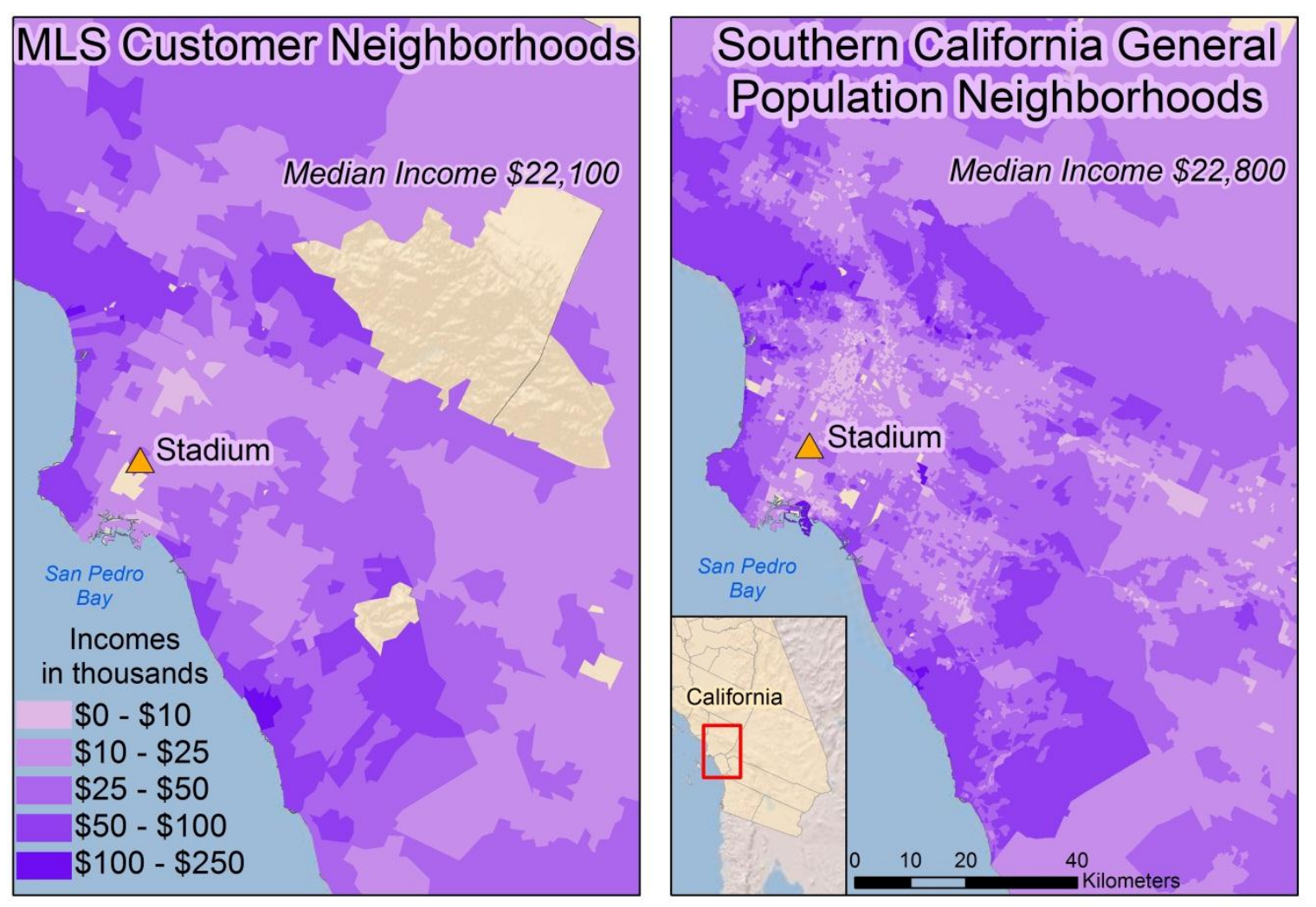

\section{Figure 5-6: $\quad$ MLS and General Population Income Map}

\subsubsection{Ethnicity}

The category of ethnicity is grouped by the U.S. Census Bureau and self-identified by survey participants. The same names that the Bureau uses for groups were used in this project. Because Chivas USA is a Hispanic-focused team, and because the Tapestry study showed that Hispanic-concentrated areas were more likely to support Chivas, a location quotient of Hispanic percentages was calculated (Table 4). Results showed that Hispanics in Chivas neighborhoods were overrepresented when compared to the region. This supports the conclusions of the literature review, that there is a relationship between Hispanic populations and soccer success. 
Table 4. Location Quotients of Ethnicity

\begin{tabular}{|l|l|l|l|}
\hline Ethnicity & $\begin{array}{l}\text { Percentage in } \\
\text { Chivas } \\
\text { Neighborhoods }\end{array}$ & $\begin{array}{l}\text { Percentage in } \\
\text { Southern California } \\
\text { Neighborhoods }\end{array}$ & $\begin{array}{l}\text { Location Quotient } \\
\text { Value }\end{array}$ \\
\hline Hispanic & $51 \%$ & $44 \%$ & 1.15 \\
\hline
\end{tabular}

The profile range was thus based on percentages of Hispanics in a neighborhood. As with the other characteristics, the range of Hispanic percentage was built upon a $75^{\text {th }}$ percentile range of all Chivas neighborhoods. Because the ideal neighborhood for Chivas would be $100 \%$ Hispanic, the range began at that value, and $75 \%$ of the neighborhoods had Hispanic percentages ranging from $20 \%$ to $100 \%$.

Figure 5-7 shows the variation of Hispanic percentages in neighborhoods where Chivas season ticket holders resided. The neighborhoods that fit the profile of $20 \%$ 100\% Hispanic are also included in this map in the bottom-left corner. 


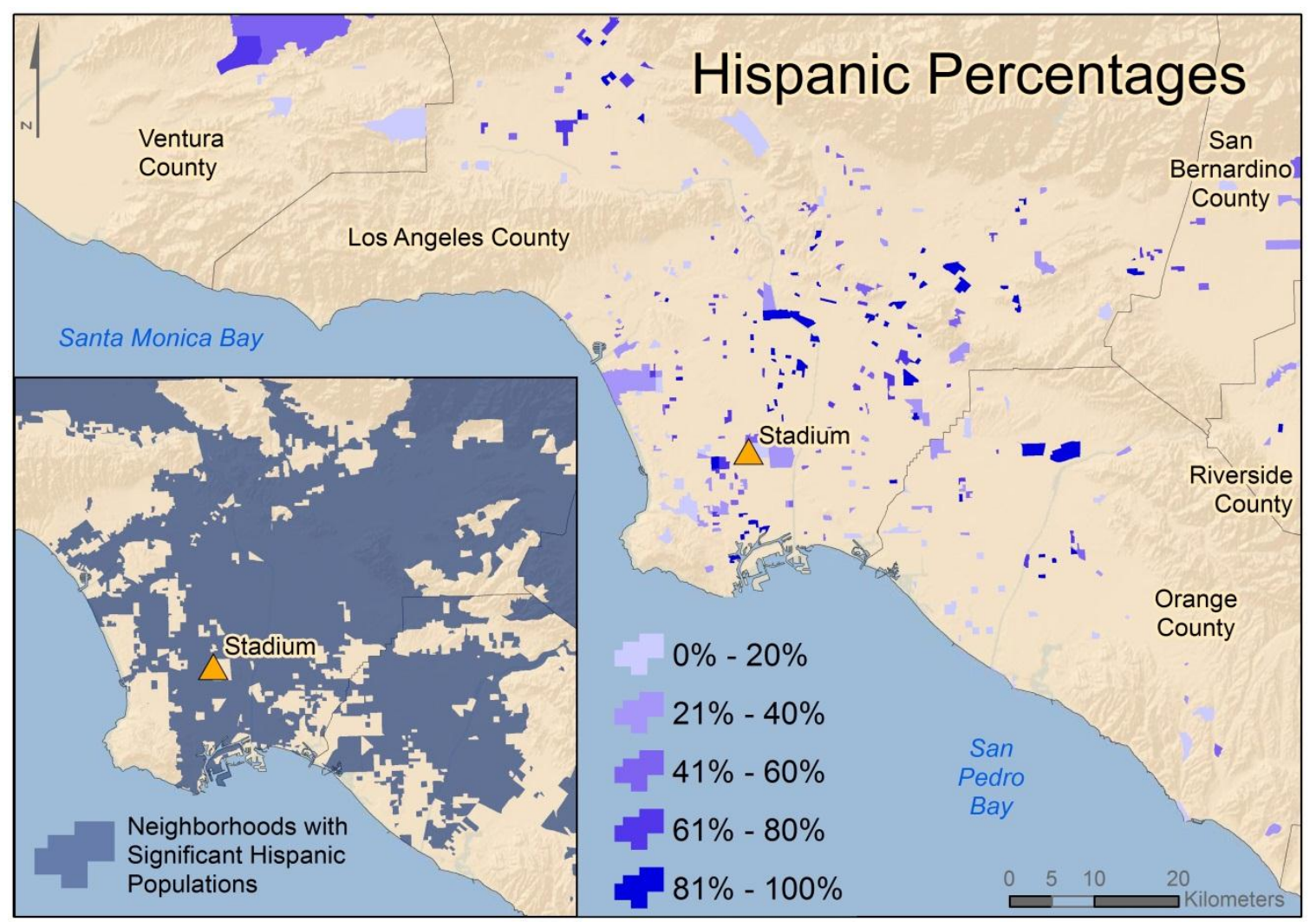

Figure 5-7: Chivas Hispanic Map

\subsubsection{Travel Cost}

Both the background literature review and the density map (Figure 5-2) indicated that travel cost was an important indicator of marketability. To facilitate a study of fan transportation to Chivas USA matches, a network analysis was conducted. Network analyses have many applications for helping understand how many persons can reach a destination, and in how much time.

Unlike many other large metropolises, Los Angeles is an automobile-oriented, low-density region (Wachs, 1993) where an overwhelming majority of residents travel by car. Its vast freeway system is incomparable to any other region in the United States and most season ticket-holders presumably travel to the stadium in private vehicles because the closest metro stations are several kilometers away. The drive times for each 
individual address to the stadium were calculated, and the median drive time of all of these was 22 minutes. Starting from zero travel cost, the $75^{\text {th }}$ percentile, following the consistent methodology, was calculated to be 34 minutes.

Both median and $75^{\text {th }}$ percentile travel cost was used to search for marketable neighborhoods (Figure 5-8). The median drive time covers much of the Los Angeles Basin and represents a driving distance most tolerable for season ticket holders. The $75^{\text {th }}$ percentile distance begins to reach into more suburban areas, extending into areas with smaller population densities and generally higher incomes. This information can be very helpful to Chivas USA's marketing strategists. If limited resources are available, they can focus efforts on the 22 minute range, but if they choose to make a stronger push in the suburban areas, they can expand efforts to the $75^{\text {th }}$ percentile range. They can also plan their strategy with the understanding that once they pass the $75^{\text {th }}$ percentile range, the likelihood of finding marketable neighborhoods may exponentially decrease farther from the stadium. 


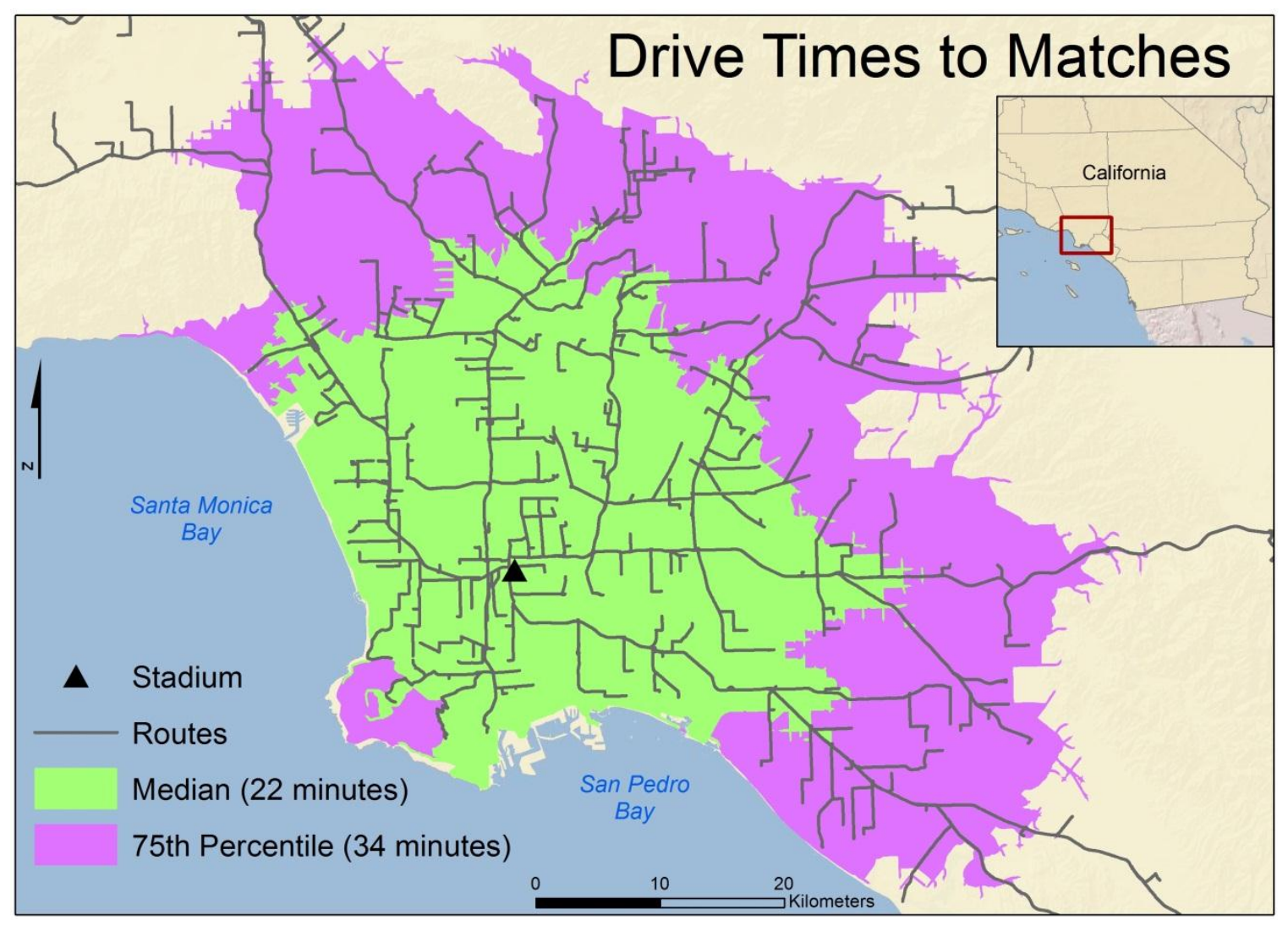

Figure 5-8: Chivas Drive Times to Matches Map

It was also important to discover drive times to the stadium from all neighborhoods in southern California for comparison (Figure 5-9). The median and $75^{\text {th }}$ percentile drive times from all southern California neighborhoods to the stadium were 33 minutes and 68 minutes respectively. This analysis showed that Chivas addresses had significantly shorter driving distances to the stadium compared to the general populace of southern California, which suggests that shorter drive times may influence a neighborhood's likelihood of containing fans. 


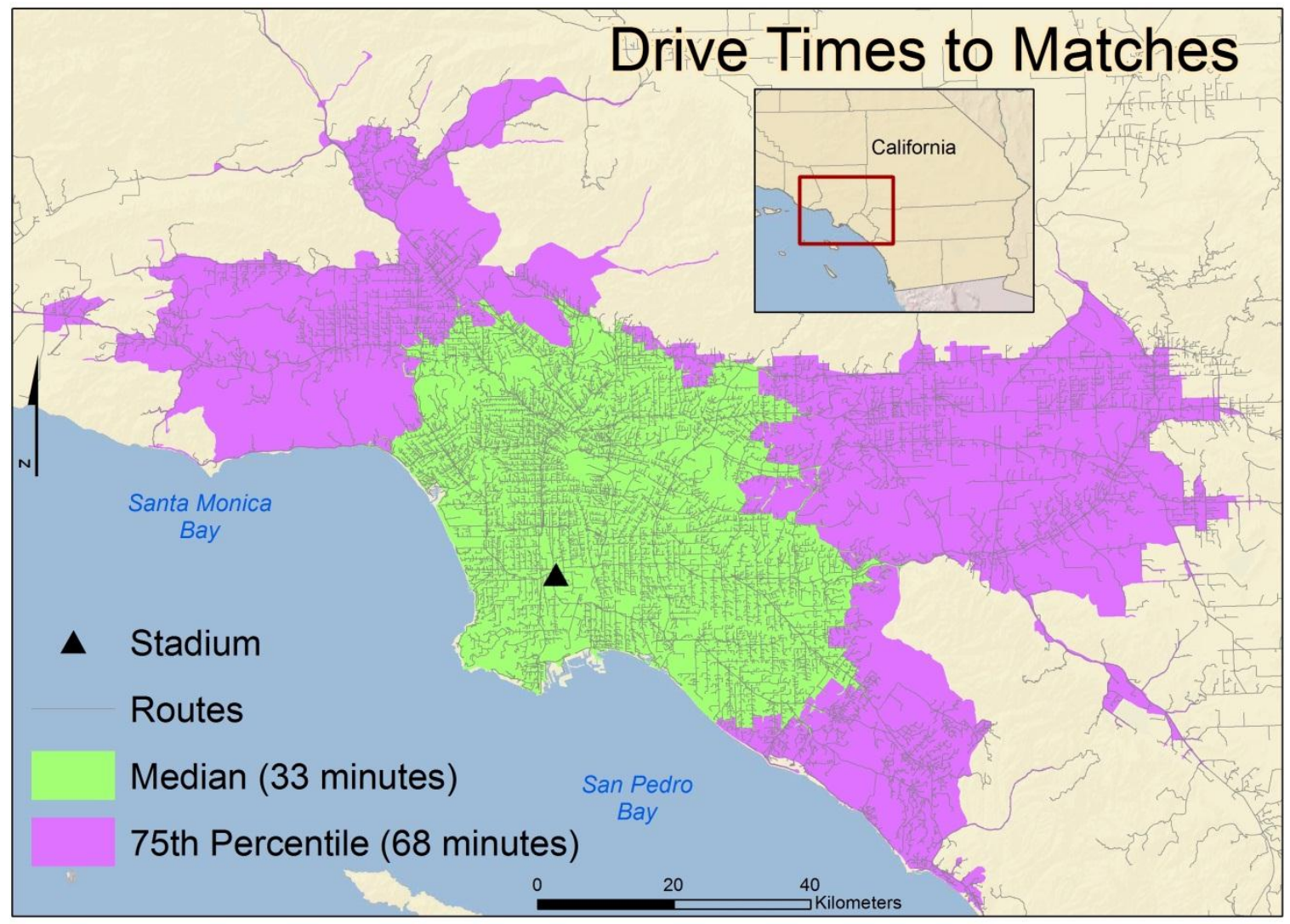

Figure 5-9: Drive Times from all Southern California Neighborhoods Map

In addition to the drive time distance, the optimal route each geocoded address would traverse to reach the stadium was also examined. With this information, the freeways passed through by the most season ticket holders were calculated (Figure 5-10). This result would be useful to Chivas USA when advertising special deals, etc., along the major freeways. 


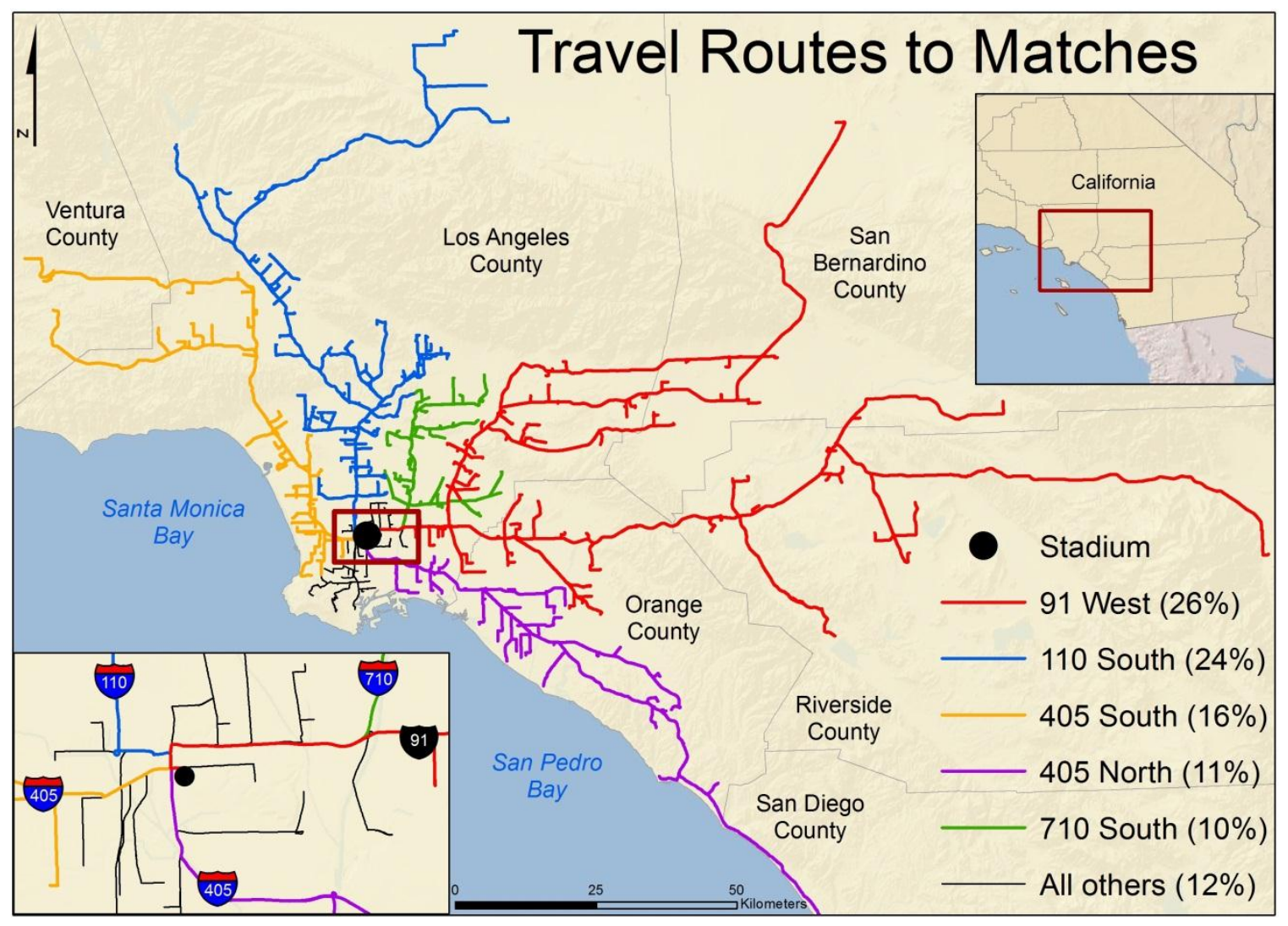

Figure 5-10: Most Used Driving Routes to Matches Map

\subsection{Finding Marketable Areas}

Analysis of these three characteristics (income, ethnicity, and transportation) produced several ranges to be used for a marketable Chivas neighborhood profile. All of these ranges were prepared on the principle of using $75^{\text {th }}$ percentiles for finding similar areas. These ranges were built into a GIS model (Figure 5-11) which found block groups with the following characteristics:

- Within a per capita income range of $\$ 10,000-\$ 44,000$

- Contain a greater than $20 \%$ Hispanic population

- Within a 22 minute drive time from the Home Depot Center, or within a 34 minute drive time from the Home Depot Center 


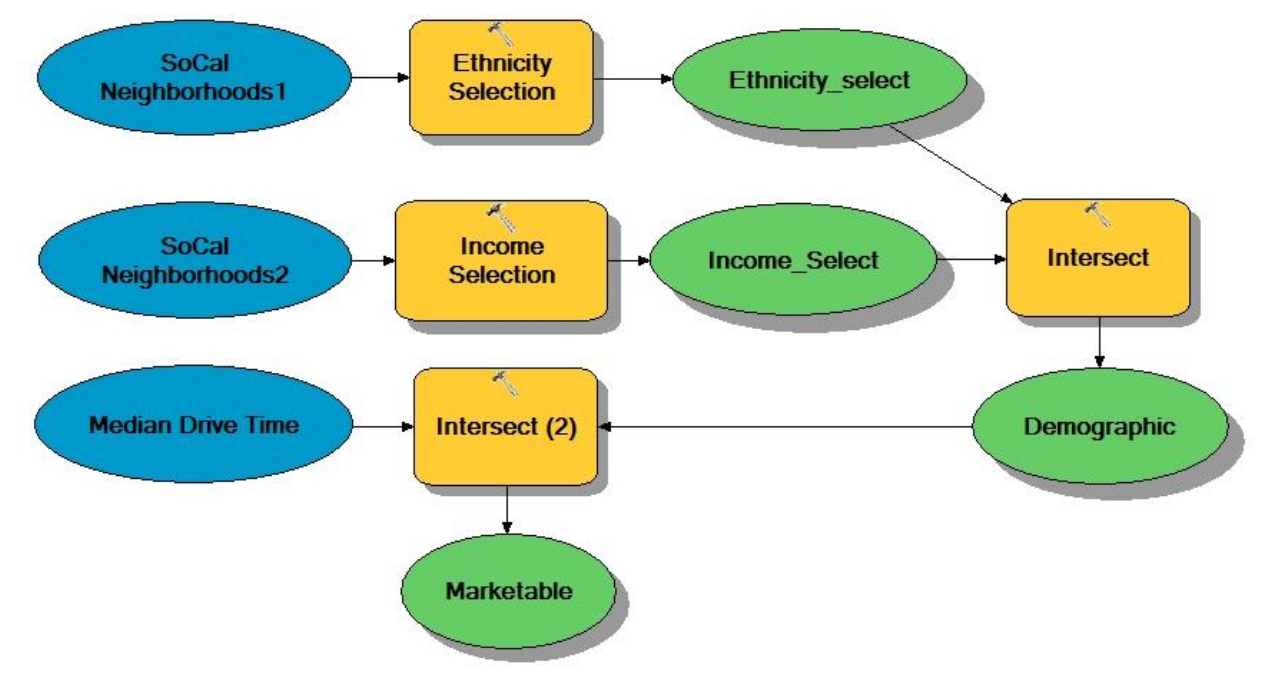

\section{Figure 5-11: Project Model}

The model was built in ArcGIS using Model builder to automate the searching process. First, the model finds the block groups that fit each criterion respectively (Figure 5-12). These block groups are then intersected with one another, and a final compilation of marketable areas is produced. 

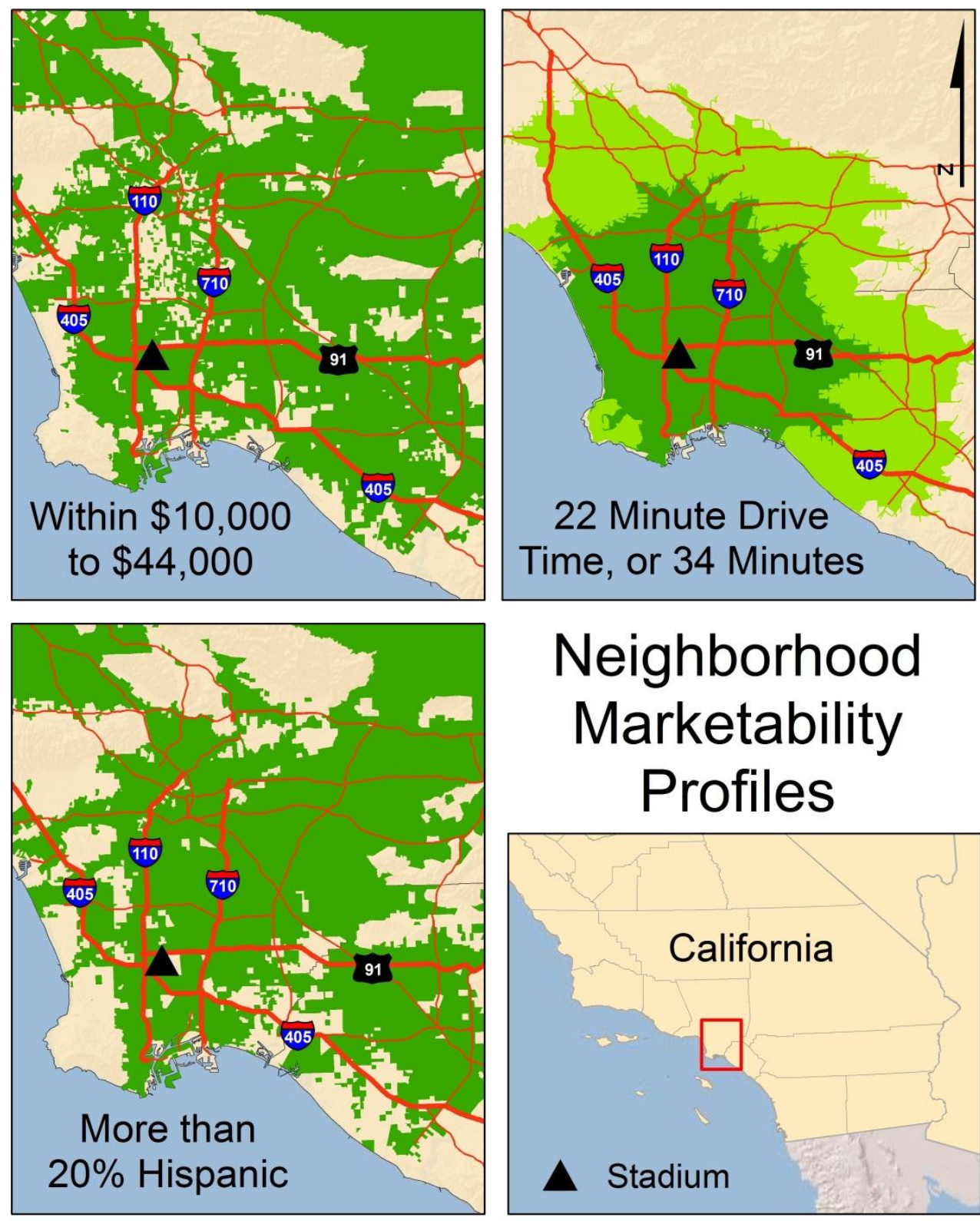

\section{Neighborhood Marketability Profiles}

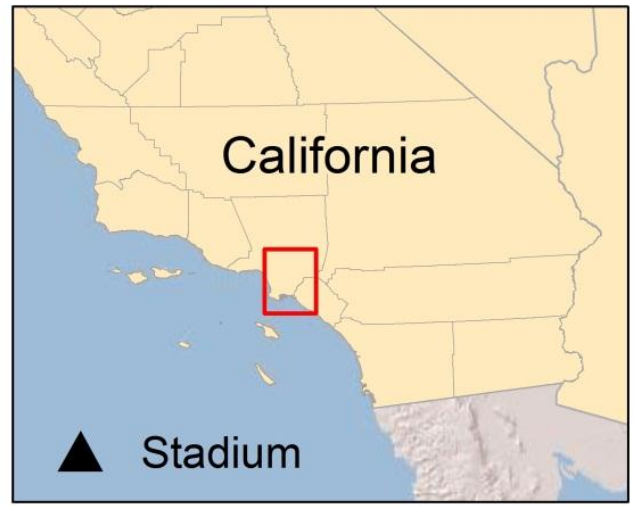

\section{Figure 5-12: Individual Neighborhood Marketability Profiles Map}

Figure 5-13 displays the final output of marketable areas for Chivas USA. Most of the marketable areas are contained within southern Los Angeles County, south of the Santa Monica Mountains and west of the San Jose Hills. These areas are commonly known as the Los Angeles Basin. Most of the areas along the Santa Monica Bay are excluded, both because the incomes are too high, and the percentages of Hispanics are 
too low, and in some cases, because the drive time is too long. There are more neighborhoods closer inland, around Interstate 405, that are marketable. However, the areas closer to the north sections of Interstate110 and Downtown Los Angeles are not ideal for marketing because incomes are too low, though there are high enough Hispanic percentages of the population.

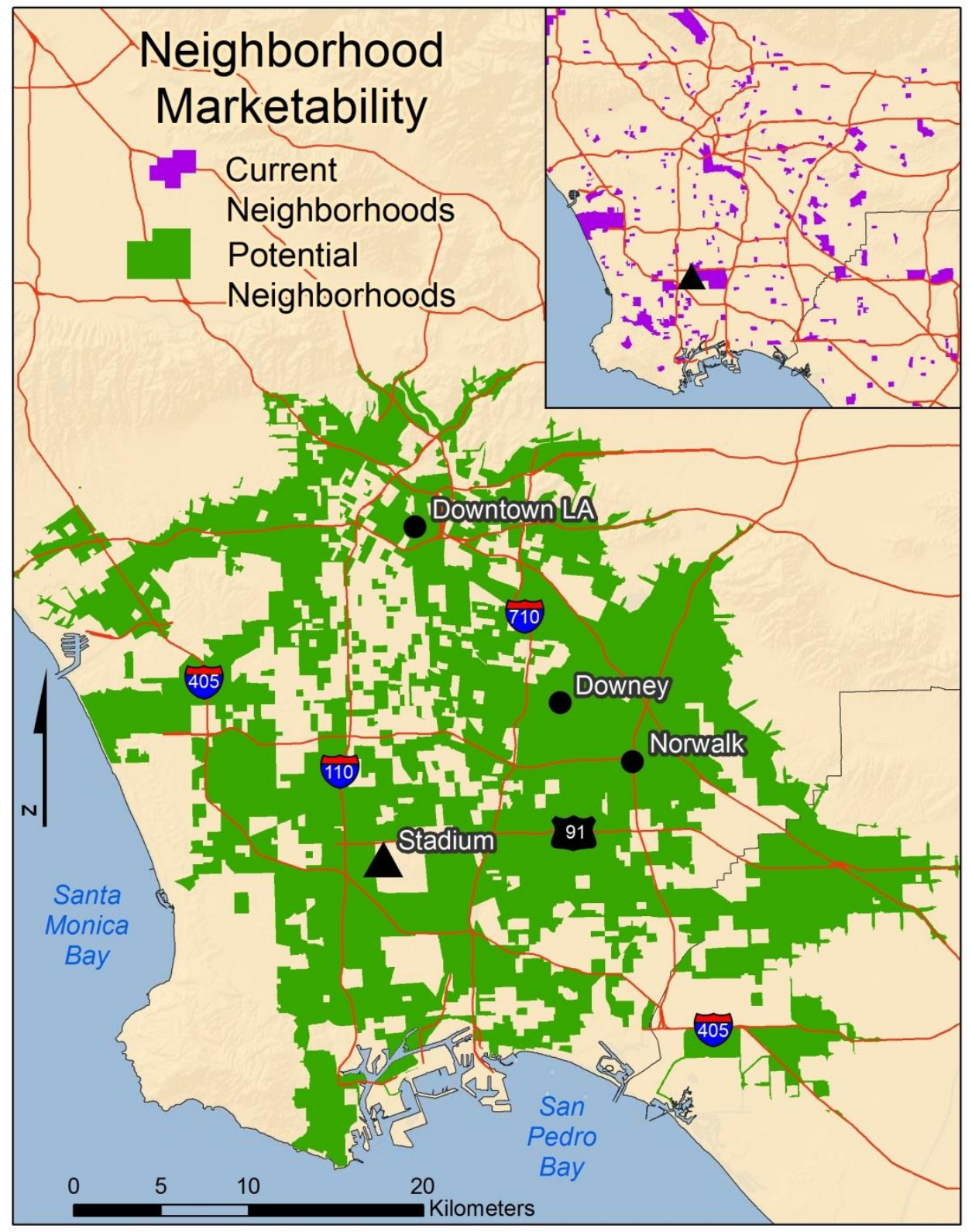

Figure 5-13: Final Marketability Map 
The South Bay, around Carson and the Home Depot Center, contains some stronger clusters of marketability (especially near the southernmost sections of Interstate 110). However, this area also contains noticeable areas of non-marketability, because of either too-low incomes or too-low percentages of Hispanics. The region with the most consistent marketability is the area east of Interstate 710 and north of State Route 91. The largest cities in this area are Norwalk and Downey, which are incidentally directly southeast of Commerce (where the mean center of all season ticket holder addresses is located). This area has the strongest overall marketability for Chivas USA. Not only does it contain a consistent trend of marketability in every direction for several kilometers, it also is the area where the mean center of season ticket holders was located. Given this information, Chivas can choose to label this area as their base and focus marketing efforts in this region. The other marketable areas can also be of great use, but more care would be required to ensure marketing is conducted in appropriate areas where there are greater local variations in marketability.

The model was also run with the $75^{\text {th }}$ percentile drive time (34 minutes). The increase in driving time adds three noticeable clusters of marketable areas (Figure 5-14). The first cluster is essentially an extension of the Commerce-Downey-Norwalk area. It adds large parts of the San Gabriel Valley. The second cluster is located in northern Orange County, and the third one is smaller, but still concentric, in the San Fernando Valley. These areas added by the longer drive time can help Chivas expand its marketing strategy to the suburban areas of greater Los Angeles. While they are farther from the stadium and thus less marketable than the median drive time areas, they represent important communities of potential that should not be ignored. 


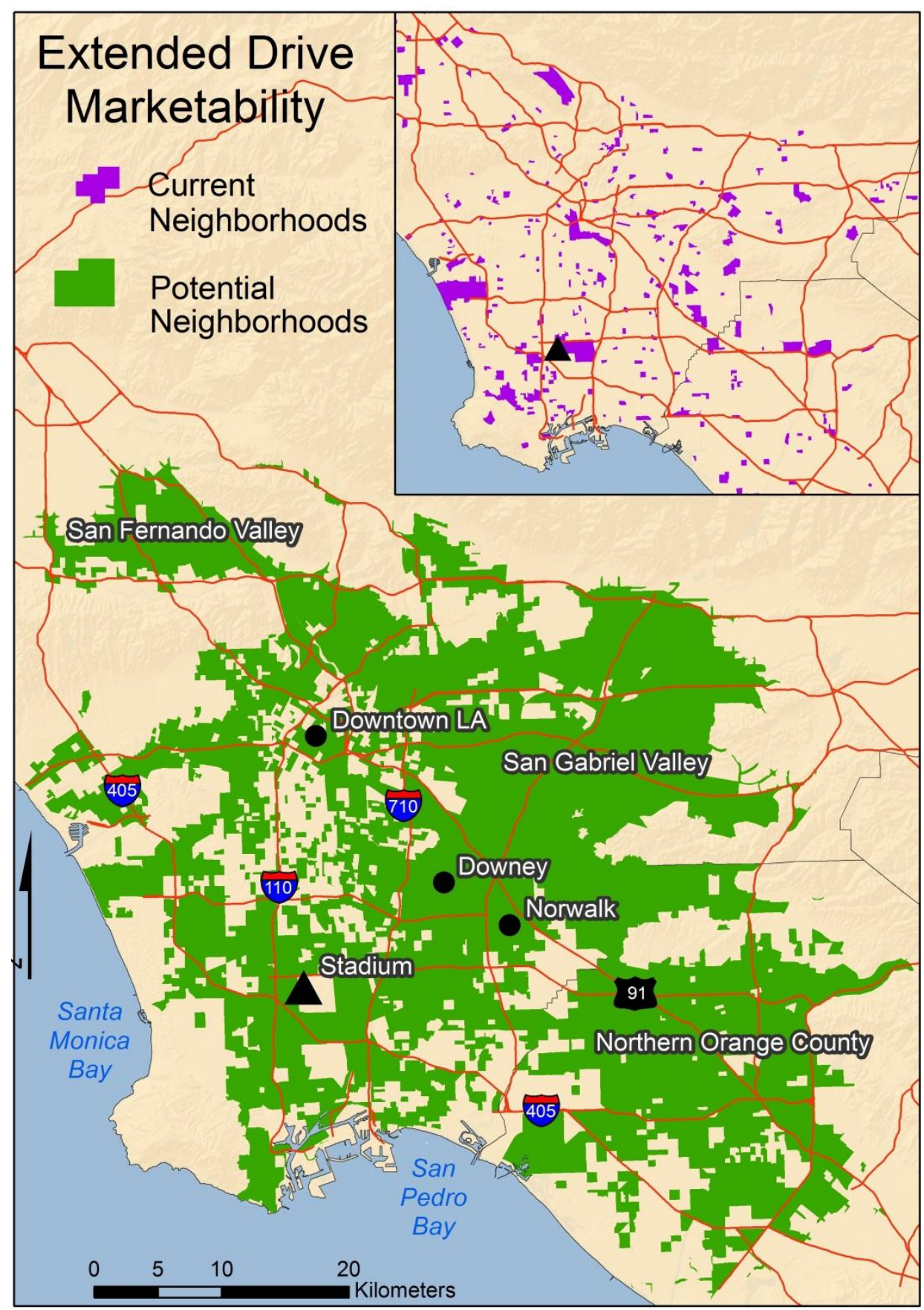

Figure 5-14: Final Marketability Map Extended

The marketability analysis needed to be tested for accuracy by examining the potential areas' overlap with the original Chivas neighborhoods (Figure 5-15). For the model to be accurate, it should have logically found many of the original Chivas 
neighborhoods to be marketable, since criteria were extracted from the Chivas neighborhoods. 162 out of 335 original neighborhoods (48\%) are found in the neighborhoods suggested by the model when the median drive time is applied. When the drive time is extended, 227 out of 335 neighborhoods are overlapped (68\%). That means that the model successfully discovered an entirely new group of neighborhoods, as well as many of the originals. In the median drive time marketable areas 2,480 neighborhoods were identified. That means that the model found seven times as many neighborhoods as the current Chivas neighborhoods. In the $75^{\text {th }}$ percentile drive time marketable areas 4,102 neighborhoods were identified. That means that this version of the model found twelve times as many neighborhoods as the current Chivas neighborhoods. These potential market increases illustrate the great assistance GIS can provide for Major League Soccer and its individual clubs. 

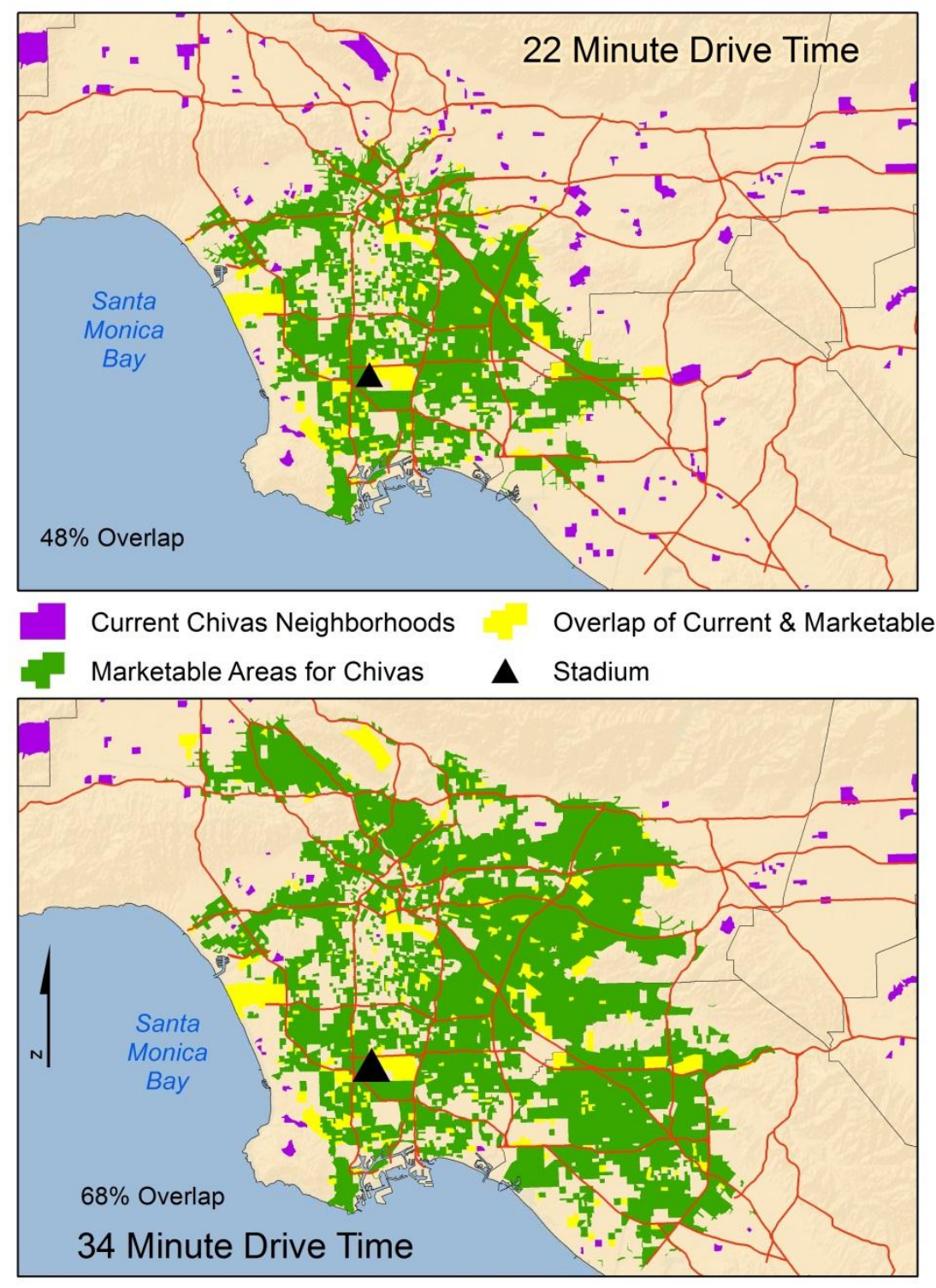

\section{Figure 5-15: Chivas Neighborhoods \& Marketable Neighborhoods Map}

\subsection{Summary}

The analysis for this study had two major objectives: define the neighborhood marketability profile, and identify similar neighborhoods in the Los Angeles area.

Building the profile involved three areas of study: income, ethnicity, and transportation.

Each area added criteria to the neighborhood profile. 
Using all of the criteria together, a GIS model was built to conduct the analysis to find similar neighborhoods. The model outputted an area which fit the profile's criteria, and was thus deemed marketable. The maps were delivered to Chivas USA, who can now use the analysis to enhance their marketing strategy in southern California. Major League Soccer may also choose to use the methodology used in this study with additional clubs. The analysis proceeded efficiently, combining multiple, diverse geoprocessing tools with several sets of data. The study exemplified the power GIS can offer in enhancing sports marketing. 



\section{Chapter 6 - Conclusions and Future Work}

There are many ways that Chivas and MLS can utilize the results of this study. From the income analysis they may adjust ticket prices to accommodate neighborhoods with per capita incomes closest to $\$ 21,600$. From the ethnicity analysis they may advertise their club more on Spanish-speaking television channels and radio stations, since these are more likely to be watched and listened to in high-percentage Hispanic neighborhoods. From the transportation analysis they could buy more billboard space on specific freeways sections. And if they chose to build a new stadium, they could choose a site that would reach the most people within a driving time of 22 minutes. The methodology used for the Chivas analysis can also be used by other clubs in the league.

When Major League Soccer first came on the scene after the successful 1994 World Cup, it was said that U.S. soccer supporters had the opportunity to join the big four of U.S. team sports (baseball, basketball, football, and hockey) but that there were significant economic, historical, sociocultural, and ideological obstacles (Delgado, 1997). GIS can be a powerful tool in the continued quest for MLS to overcome such obstacles.

While both GIS and sports marketing are not new innovations or practices, their combination does appear to be a largely untapped resource. Although this study has brought about the discovery of a neighborhood profile using GIS, and shown a professional sports club's specified marketable geographic areas, it was still a preliminary study. This is because it represents only a fraction of what GIS could theoretically accomplish for this club, the entire league, and for any other sports league. All neighborhoods have attributes which make them more or less marketable for a sports team. As these attributes are discovered, recorded, and analyzed, many trends, 
relationships, and tendencies may yet be discovered which may be lucrative to those involved with the league or club's marketing efforts. They may also be of interest to academics seeking to further understand neighborhoods and their relationships with sports and recreation.

\subsection{Future Analysis}

While this study has analyzed season ticket holders of a single season for a single club, a much more expansive study could be done. What is the geographic variation between general fans and those who purchase tickets for an entire MLS season? Furthermore, what of the differences between Chivas USA and other MLS clubs, particularly the Los Angeles Galaxy who currently share a stadium with Chivas? And what of the differences between Major League Soccer and other leagues such as the English Premier League or the Mexican Primera División? Such studies might reveal differences or similarities in the neighborhoods of other nations and regions and their relationships to soccer clubs.

\subsubsection{Challenges and Opportunities}

As so often is the case, the greatest challenge to such efforts might be access to data. Multi-million dollar clubs and leagues need to be contacted and they must agree to share their data. Also, once data are acquired, they are often stored in formats difficult to translate into a GIS. However, the results may be well worth overcoming the challenges.

Another route to take in GIS and sports marketing could be the inclusion of time as a variable. If the research conducted in this study were duplicated for all of Chivas USA's seasons, much could be discovered about changes in the fan base over time, as well as why those changes may have occurred. In this study, time was not used since season ticket holders did not change much over several seasons. But this might not be 
the case with the general fans. It could be that the average income for neighborhoods with general Chivas fans has increased or decreased since its inaugural season. Or perceived changes could merely be mimicking an overall drop in the California economy while the locations of fans did not change much. Such studies could be very revealing to Major League Soccer, for them to learn where they may be succeeding or failing. Most temporal GIS technologies are still in the research phase (Yuan, 2009), and therefore the new application of GIS in sports marketing might be further enhanced using the variable of time.

One study of sports and popular culture noted that rapidly-growing technologies such as the internet and smart phones mean success can no longer be measured by attendance and television only (Kotler, Rein, \& Shields, 2006). Fortunately, GIS is riding the wave of online technology, through volunteered geographic information (VGI) which can "act as a very useful source of commercial intelligence" (Goodchild, 2007, p. 220). VGI has proved useful in many arenas, notably in the 2010 Haiti Earthquake, where individuals assisted by contributing data to online portals such as OpenStreetMap and Ushahidi (Gorman, Graham, Shelton, \& Zook, 2010). Almost anyone with internet access can volunteer their geographic information by, for example, naming streets from memory into OpenStreetMap to help guide emergency responders. VGI has proven to be highly beneficial to disaster relief, and it could certainly be the basis for more GIS research for Major League Soccer (MLS). Perhaps the MLS website could employ VGI, by letting participants input locations where they saw someone wearing a MLS jersey, or where there are restaurants where fans can gather to watch MLS matches on television. Furthermore, a GIS analyst could monitor tweets that mention MLS and plot them onto a 
map. This information could suggest to the league more about the geographical distributions of their fans. Future online work could also include using this project's model in a web application, as geoprocessing is part of the functionality of Esri's ArcGIS Server (Fu \& Sun, 2011).

Further research could involve remote sensing technology. Hyperspectral data allow analysts to "identify the type and proportion of different materials within an individual picture element" (Jensen, 2005, p.27). An analyst studying soccer could identify a soccer field using this data, and then highlight all the areas in southern California that have the same makeup. This would theoretically show all the soccer fields in southern California, facilitating distribution research. A challenge would include differentiating between soccer and American football fields.

\subsection{Final Conclusion}

This study was initiated with two major goals: first, develop a profile of neighborhoods most marketable for Chivas USA based on season ticket sales in 2010, and second, identify all of the neighborhoods that fit that profile. Accomplishing these two goals should help enhance Chivas' marketing strategy and open the door for more GIS implementation in Major League Soccer.

The neighborhood profile for Club Deportivo Chivas USA had a per capita income range of $\$ 10,000$ to $\$ 44,000$, a Hispanic percentage range of $20 \%$ to $100 \%$, and drive time ranges of 0 to 22 and 0 to 34 minutes. Using this profile, marketable areas were discovered in greater Los Angeles, almost always inward from the coast, and very often distanced away from the foothills. The most consistent concentration was southeast 
of downtown Los Angeles around Commerce, Downey, and Norwalk. All of this information was passed on to the client.

While this study was designed initially to benefit Major League Soccer, it has also hopefully become a springboard for which further research can be conducted, and act as a starting point from which GIS can be implemented into the broader sports marketing world. 



\section{Works Cited}

Alba, R., Logan, J., Zhang, W. (2002). Immigrant Enclaves and Ethnic Communities in New York and Los Angeles. American Sociological Review, 67, 299-322.

Arreola, D. D. (2004). Hispanic Spaces, Latino Places: Community and Cultural Diversity in Contemporary America. Austin, TX: University of Texas Press.

Baade, R. A., Baumann, R., \& Matheson, V. A. (2008). Selling the Game: Estimating the Economic Impact of Professional Sports through Taxable Sales. Southern Economic Journal, 74, 794-810.

Bale, J. (2007). The Changing Face of Football: Stadiums and Communities. Soccer and Society, $1,1$.

Barber, G. \& Burt, J. (1996). Elementary Statistics for Geographers. New York: Guilford Press.

Barget, E. \& Gouget, J. (2007). The Total Economic Value of Sporting Events Theory and Practice. Journal of Sports Economics, 8, 165-182.

Bolstad, P. (2008). GIS Fundamentals: A First Text on Geographic Information Systems. White Bear Lake, MN: Eider Press.

Buckley, A., Kimerling, A., Muehrcke, J. \& Muehrcke, P. (2009). Map Use: Reading and Analysis. Redlands, CA: Esri Press.

Brunsdon, C., Comber, A., Green, E. (2008). Using a GIS-Based Network Analysis to Determine Urban Greenspace Accessibility for Different Ethnic and Religious Groups. Landscape and Urban Planning, 86, 103-114.

Common, M. (1973). A Note on the Use of the Clawson Method for the Evaluation of Recreation Site Benefits. Regional Studies, 7, 4.

Delgado, F. (1997). Major League Soccer: The Return of the Foreign Sport. Journal of Sport and Social Issues, 21, 285-297.

Downward, P. \& Riordan, J. (2007). Social Interactions and the Demand for Sport: An Economic Analysis. Contemporary Economic Policy, 25, 518-537.

Eitzen, D. (2000). Sport in Contemporary Society: An Anthology. London: Worth Publishers.

Feehan, P., Forrest, D., \& Simmons, R. (2003). A Spatial Cross-Sectional Analysis of the Elasticity of Demand for Soccer. Scottish Journal of Political Economy. 49, 336355. 
Foer, F. (2005). How Soccer Explains the World: An Unlikely Theory of Globalization. New York: Harper Perennial.

Fu, P. \& Sun, J. (2011). Web GIS: Principles and Applications. Redlands, CA: Esri Press.

Garcia, J. \& Rodriguez, P. (2002). The Determinants of Football Match Attendance Revisited: Empirical Evidence from the Spanish Football League. Journal of Sports Economics, 3, 18-38.

Ging, L. C., Hoffmann, R., \& Ramasamy, B. (2002). The Socio-economic Determinants of International Soccer Performance. Journal of Applied Economics, 5, 253-272.

Giulianotti, R. (1999). Football: A Sociology of the Global Game. Cambridge, UK: Polity Press.

Goodchild, M. (2007). Citizens as Censors: the World of Volunteered Geography. Geojournal, 69, 211-221.

Gorman, S., Graham, M., Shelton, T., Zook, M. (2010). Volunteered Geographic Information and Crowdsourcing Disaster Relief: A Case Study of the Haitian Earthquake. World Medical and Health Policy, 2, 2.

Hellerman, S. L., \& Markovits, A. S. (2001). Offside: Soccer and American Exceptionalism. Princeton, NJ: Princeton University Press.

Hornby, N. (1998). Fever Pitch. New York: Riverhead Trade.

Jensen, J. (2005). Introductory Digital Image Processing: A Remote Sensing Perspective. Upper Saddle River, NJ: Pearson Prentice Hall.

Jewell, R. \& Molina, D. (2005). An Evaluation of the Relationship between Hispanics and Major League Soccer. Journal of Sports Economics, 6, 160-177.

Kiil, A., Kjaer, T., Pedersen, L. (2010). Soccer Attendees' Preferences for Facilities at the Fionia Park Stadium: An Application of the Discrete Choice Experiment. Journal of Sports Economics, 12, 179-199.

Kotler, P., Rein, I., \& Shields, B. (2006). The Elusive Fan: Reinventing Sports in a Crowded Marketplace. New York: McGraw-Hill Professionals.

Kuper, S. \& Szmanski. S. (2009). Soccernomics: Why England Loses, Why Germany and Brazil Win, and Why the U.S., Japan, Australia, Turkey - and Even Iraq-are Destined to Become the Kings of the World's Most Popular Sport. New York: Nation Books. 
Miller, F. (2011). Getting to Know Esri Business Analyst. Redlands, CA: Esri Press.

Miller, R. M. \& Crolley, L. (2007). Football in the Americas: Futbol, Futebol, Soccer. London: University of London.

Morris, D. (1981). The Soccer Tribe. London: Jonathon Cape.

Morrow, S. (2003). The People's Game? Football, Finance, and Society. New York: Palgrave Macmillan.

Newsham, G. (2006). Once in a Lifetime: The Incredible Story of the New York Cosmos. New York: Grove Press.

Randall, A. (1994). A Difficulty with the Travel Cost Method. Land Economics, 70, 8896.

Smith, M. K. (2005). Factors in the Adoption of Geographic Information Systems in Sports Marketing (Masters Thesis). Retrieved from Proquest. (1431823)

Tomlinson, R. (2007). Thinking about GIS: Geographic Information System Planning for Managers. Redlands, CA: Esri Press.

Verjee, F. (2011). GIS Tutorial for Humanitarian Assistance. Redlands, CA: Esri Press.

Wachs, M. (1993). Learning from Los Angeles: Transport, Urban Form, and Air Quality. Transportation, 20, 329-354.

Yuan, M. (2009). Challenges and Critical Issues for Temporal GIS Research and Technologies. In Karimi, H. (Ed.), Handbook of Research on Geoinformatics. (pp. 144-153). doi:10.4018/978-1-59140-995-3.ch019.

Zeiler, M. (1999) Modeling our World: The Esri Guide to Geodatabase Concepts. Redlands, CA: Esri Press. 



\title{
Appendix A. Esri Community Tapestry Descriptions
}

\author{
1. Las Casas
}

Demographic

Las Casas residents are the latest wave of western "pioneers." Nearly half were born outside the United States; 84 percent are Hispanic. Households are dominated by families, mainly married couples with children (42 percent) and single-parent families (21 percent). The median age is 25.7 years; approximately 50 percent are younger than age 30 . The average household size of 4.32 is the highest of the Tapestry segments.

\section{Socioeconomic}

The median household income of $\$ 40,559$ and the median net worth of $\$ 14,034$ are low compared to the national medians. Most households derive their income from wages and salaries; some receive Supplemental Security Income or public assistance income. The service and manufacturing industry sectors provide most of the jobs for these residents. Many work part-time; unemployment is nearly double the US rate. Educational attainment levels are much lower than national levels. Nearly 20 percent of the population aged 25-plus haven't graduated from high school; only 20 percent have attended college.

\section{Residential}

Las Casas neighborhoods are located primarily in California. Six in ten households rent. The median value for owner-occupied homes is $\$ 207,860$. There is strong demand for 
housing in these neighborhoods; vacancy rates are lower than average. Housing is a mix of older apartment buildings, single-family dwellings, and townhomes. Most of the housing units were built before 1970 .

\section{Preferences}

The large size of Las Casas households limits their discretionary income. The presence of children influences their spending habits. They live modest lifestyles. Many drive older vehicles. This is a strong market for purchases of baby and children's products. They typically shop for groceries at Ralphs, Vons, and the am/pm convenience store. They eat fast food at Carl's Jr., Del Taco, or Jack in the Box. Improving or remodeling their homes isn't important to them. Typically, households own one TV set and do not subscribe to cable. They watch daytime or sports programs on TV, particularly soccer and weight lifting. Hispanic radio is, by far, their favorite radio format; however, they also listen to variety and contemporary hit radio programs. They play soccer and baseball or go to the movies.

\section{Urban Villages}

\section{Demographic}

Urban Villages neighborhoods are multicultural enclaves of young families, unique to densely populated cities in "gateway" states, primarily California. The average family size of 4.1 people is the second largest in the Tapestry system. Household types are married couples with (approximately 40 percent) and without children, single parents, and other family types. The median age is 31 years. Population diversity is especially 
high; virtually every race and culture is represented in these communities. Asians comprise 11.2 percent of the total population. Sixty-one percent of the population is Hispanic, primarily of Mexican origin. Slightly more than one-third of the population is foreign born.

\section{Socioeconomic}

Fifteen percent of Urban Villages residents aged 25 years or older have not completed high school; more than one-fourth are high school graduates, and two-fifths have attended college. The labor force participation rate of 60 percent is slightly lower than the US rate; the unemployment rate of 14.4 percent is higher. Many households have two wage earners, most of whom work in the manufacturing, health care, retail trade, construction, and educational services industry sectors. The median household income is $\$ 62,837$; the median net worth is $\$ 104,128$.

\section{Residential}

Eighty-four percent of Urban Villages households are located in California. Most homes are older, single-family structures. Approximately two-thirds of the housing units were built before 1970. The home ownership rate is 69 percent, and the median home value is $\$ 257,168$. Approximately 12 percent live in apartments, and at 3.6 percent, vacancy rates barely support turnover. A typical household owns multiple vehicles; 27 percent own three or more.

\section{Preferences}

Family and home items are household budget priorities for Urban Villages residents. Because most of their housing is older, residents repaint and remodel bathrooms and 
replace carpeting and roofing. Many buy groceries and baby products. They shop for groceries at Ralphs and Vons. They vacation in Hawaii and Mexico. Leisure time is a family affair; residents visit Sea World regularly. They also like to go to the movies, eat fast-food at Carl's Jr. and Del Taco, and visit family restaurants such as Denny's. Urban Villages residents rent foreign films on DVD and listen to Hispanic, contemporary hit, and variety radio. Although most watch TV, sports programming is not as popular here as in other markets. They have recently bought iPods and giant-screen TVs.

\section{Rural Bypasses}

\section{Demographic}

The age and household composition of the Rural Bypasses market is very similar to US distributions. Half of the households consist of married-couple families, 15 percent are single-parent families, and 7 percent are other family types. One-fourth of the households consist of a single person. The median age for this segment is 38.3 years, near the US median of 37 years. Fifty-eight percent of the residents are white; 35.5 percent are black.

\section{Socioeconomic}

The median household income is $\$ 28,082$. Wages and salaries provide the primary sources of income; however, many depend upon Social Security, Supplemental Security Income, and public assistance for support. Because of low home values and household debt, the median net worth of $\$ 22,235$ is below the median household income. Overall, two in three residents aged 25 years and older have graduated from high school; the population with a bachelor's degree is one-third that of the US level. Employed residents 
work in a variety of occupations, with a slightly higher percentage in blue-collar occupations. Higher-than-average proportions of employed residents work in the agricultural, mining, manufacturing, and construction industry sectors. Compared to US levels, the labor force participation rate of 50 percent is low and the unemployment rate of 14.6 percent is high.

\section{Residential}

Open space, undeveloped land, and farmland are found in Rural Bypasses neighborhoods, located almost entirely in the South. Families live in small towns along country back roads. Residents enjoy the open air in these sparsely populated neighborhoods. Most houses are modest, single-family dwellings; 32 percent are mobile homes. Home ownership is at 76 percent; the median home value is $\$ 63,328$, one of the three lowest of the Tapestry segments. Most housing in this market was built after 1969. The vacancy rate of 16 percent is high.

\section{Preferences}

Typical of their country lifestyle, Rural Bypasses residents prefer to drive trucks and SUVs and listen to country radio. To save money, they eat at home and maintain their homes and gardens themselves. In areas with no cable access, some residents install satellite dishes to watch TV. They frequently watch sports on TV, NASCAR and other auto races, college football games, and fishing programs. They read fishing and hunting magazines. Conservative with their long-distance calls, resident demand for cost-effective cellular services is growing. They shop at discount stores, preferably at Wal-Mart. They also order from catalogs and from their Avon representatives. They 
shop at home improvement stores such as Lowe's and fill prescriptions at the local WalMart Pharmacy instead of regular pharmacies. This is the top Tapestry segment to own and/or buy new motorcycles.

\section{Heartland Communities}

\section{Demographic}

Settled and close-knit, residents of Heartland Communities have a median age of 42.8 years. Approximately half of the residents have already retired, many in the same towns where they have lived and worked their whole lives. Nearly half are aged 55 years or older. Although married-couple families comprise nearly half of the household types and almost one-third are singles who live alone, other family types and shared housing are also represented. Children are found in 30 percent of the households. Diversity is minimal; nearly 9 in 10 residents are white.

\section{Socioeconomic}

The median household income is $\$ 35,160$. Two-thirds of the households earn wage and salary income, and 39 percent receive Social Security benefits. Because of low home value, their median net worth is $\$ 46,091$. Employed residents work in occupations ranging from management positions to unskilled labor jobs; approximately 40 percent are employed in service industries. The percentage of the population aged 25 years or older that has completed high school is higher than the US level; the percentage that has attended college is far lower than the US figure.

\section{Residential}


Home to six million people, Heartland Communities neighborhoods are found primarily in small towns scattered across the Midwest and South. Low-density neighborhoods dominate, with older homes in urban clusters and rural, nonfarm areas. More than half of the housing units were built before 1960. Home ownership is at 71 percent; the median home value is $\$ 78,489$, less than half of the US median. More than three-fourths of the housing is single-family dwellings.

\section{Preferences}

Heartland Communities residents invest time and money in their cherished homes and communities. They take pride in their gardening skills and in growing their own vegetables. Many homes own a riding lawn mower to keep up their relatively large lots. Residents tackle home improvement projects such as exterior painting and faucet replacement and shop at Ace Hardware or Lowe's. Many residents order items from catalogs, QVC, and Avon sales representatives. They also shop at Wal-Mart or Kmart and buy groceries at Wal-Mart Supercenters. Favorite restaurants include Golden Corral and Cracker Barrel. The residents in this segment rarely travel by plane. Heartland Communities residents have a distinctly country lifestyle. They go hunting and fishing. They also read gardening, fishing, and hunting magazines and listen to country music and auto races on the radio. Reading two or more Sunday newspapers is important to them. Some join fraternal orders or religious clubs and even get involved with local politics. Many Heartland Communities households subscribe to cable and usually watch news programs and movies on TV. 